\title{
Effect of The Surfactant Loaded Amount Into The Bentonite on The Elimination of Two Anionic Dyes: Adsorption, Kinetics, and Isotherm Studies
}

\section{Brahim Guezzen}

Tlemcen University

Mehdi Adjdir ( $\square$ mehdi.adjdir@daad-alumni.de)

University Dr. Moulay Tahar

Abdelkader Elaziouti

University of Science and Technology Oran Mohammed Boudiaf (USTO M.B)

Mohamed Amine Didi

Tlemcen University

\section{Research Article}

Keywords: Hybrid-Bentonite, Adsorption, Anionic dye, Kinetics, Isotherm

Posted Date: March 22nd, 2021

DOI: https://doi.org/10.21203/rs.3.rs-306511/v1

License: (9) This work is licensed under a Creative Commons Attribution 4.0 International License.

Read Full License 
Effect of the surfactant loaded amount into the bentonite on the elimination of two anionic dyes: Adsorption, Kinetics, and Isotherm studies

Brahim Guezzen ${ }^{1,2}$, Mehdi Adjdir ${ }^{2,3}$, Abdelkader Elaziouti ${ }^{4}$ and Mohamed Amine Didi ${ }^{1}$

${ }^{1}$ Laboratory of Separation \& Purification Technology, Department of Chemistry, Faculty of Sciences, Tlemcen University, Box 119, Algeria

${ }^{2}$ Department of process engineering, faculty of technology, University Dr. Moulay Tahar, Saida, Algeria.

${ }^{3}$ Laboratory of Applied Organic Synthesis, Faculty of Exact and Applied Sciences, University Oran1 Ahmed Ben Bella, BP 1524 El M'Naouer, 31000 Oran, Algeria

${ }^{4}$ Laboratory of Electron Microscopy and Materials Science L.E.M.M.S, University of Science and Technology Oran Mohammed Boudiaf (USTO M.B), PB 1505 El M'naouar, 31000 Oran, Algeria

Correspondant Authors: Email: brahim.guezzen@univ-saida.dz, mehdi.adjdir@univ-saida.dz 


\section{Abstract}

The present work focused on the preparation of hybrid-bentonite adsorbents by treating sodium bentonite $(\mathrm{Na}-\mathrm{B})$ with different amounts of hexadecyltrimethylammonium bromide HDTMA $^{+}$ $\left.\mathrm{Br}^{-}\right)$, corresponding to 50, 100 and $200 \%$ the value of the cation exchange capacity (CEC). The samples prepared, namely 50HDTMA-B, 100HDTMA and 200HDTMA-B, were characterized by different techniques including Fourier transform infrared spectroscopy (FTIR), X-ray diffraction (XRD) and thermogravimetric analysis (TGA ). The removal efficiency of two anionic dyes, namely. Congo Red (CR) and Indigo Carmine (IC), from aqueous solutions, was studied as a function of the amount of HDTMA, contact time, hybrid adsorbent and initial dye concentration. In addition, a kinetic study was conducted to fit the experimental data in order to compare the adsorption rate constants and the equilibrium sorption capacities of anionic dyes on the prepared materials. The results obtained indicated that the adsorption kinetics of clay samples could be best described by the pseudo-second-order model, and the adsorption capacity of the hybrid-Bentonite is affected by the amount of modifier used. Based on Weber-Morris intra-particle diffusion equation, it was found that the

CR and IC dyes diffused faster as the cationic surfactant loading increased from 0 to $100 \%$ of the CEC value. The Langmuir isotherm exhibited the best fit, with an adsorption capacity equal to 292 and $289 \mathrm{mg} \mathrm{g}^{-1}$, for CR and IC dyes, respectively.

KEYWORDS: Hybrid-Bentonite; Adsorption; Anionic dye; Kinetics; Isotherm 


\section{Introduction}

Textile dyeing is a process that has been practiced since the early days of mankind. At the beginning, only natural dyes were used, but afterwards, they were progressively replaced by synthetic dyes[1] The presence of dyestuffs in effluents discharged from factories does pose serious threats to the environment when they are released in the biosphere without prior treatment. Dyestuffs are dangerous pollutants that have serious effects on the aquatic flora and fauna, but also on the human and animal populations that consume untreated water as well.[2] Many synthetic coloring dyes can be seriously harmful to public health and may engender allergies in humans; they can also affect the aquatic life and even the food chain.[3]. Congo red (CR) and indigo carmine (IC) have extensively been applied in textile dyeing processes due to their technical simplicity, low purchase and production costs, ease of application, durability and also because they are available in various colors. $[4,5]$ These two dyes (CR and IC) are classified as azo dyes and vat dyes, respectively; they both carry negative charges on their molecules. Furthermore, it has widely been reported that the discharge of CR and IC into the environment may lead to skin and eye irritation, injuries to the cornea and conjunctiva, dermatitis and cancer for humans.[6, 7] For this reason, an effective treatment is urgently required for the purpose of eliminating these harmful substances from the environment. Indeed, several techniques, such as coagulation and flocculation, reverse osmosis, oxidation or chemical reduction, adsorption, photocatalytic degradation, etc., have been employed in the removal of dyes from aqueous systems.[8, 9]

The adsorption technique proved to be effective and relatively cheap for the elimination of dyes[10] because this process is highly effective in purifying contaminated water. The use of clays as adsorbents is actually of great interest in the treatment of industrial wastewater because they present high surface area, with a negative charge, high cation exchange capacity and wide availability in nature. 
Nowadays, it is widely admitted that natural clays are poor adsorbents of anionic dyes. For this reason, it was decided to modify these natural clays by means of surfactants, by introducing an organic phase on the clay interlayer surface that acts as a partitioning medium for the anionic contaminants. Recent works have suggested that chemically modified clays represent a novel and promising class of adsorbent materials. Such modification may consist of replacing the compensating ions by alkyl ammonium ions. The clay surface is thus converted from an initially hydrophilic state to a hydrophobic state, which makes it possible to give rise to strong interactions with organic molecules either in the vapor state or dissolved in water. The adsorption of anionic dyes on organo-clays has been extensively investigated.[11, 12] The adsorption capacity and adsorption process depend on the molecular structure, amount of modifier or ammonium cations, chemical properties of organic compounds, and surface area of clay mineral.[13-15]. Few studies are available on the removal of CR and IC dyes by hybridclays. In this context, Dazhong Shen et al.[16] were able to remove 95\% IC from water using polydiallydimethylammonium modified Bentonite (PDADMA-Bentonite) at a dosage of 0.75 $\mathrm{g} \mathrm{L}^{-1}$. As for Chenglong Xia et al.[17], they reported that the adsorption capacities of hectorites modified with cetyltrimethyl ammonium bromide (CTAB) and octadecylamine, for CR dye, were greatly improved compared to natural hectorite. In addition, Li Wang et al.[18] indicated that the synergistic effects of several factors, such as the changes in the crystalline structure, specific surface area and average pore size, may help to increase the adsorption capacity of cethyltrimethylammonium-modified montmorillonite (CTAB-MMT) when appropriate amounts of CTAB are used (2.0 CEC) in the case of CR dye elimination. The present study aimed at preparing hybrid-clays through the modification of Bentonite clay using cationic surfactants. Its main purpose consisted in highlighting the remarkable potential of hexadecyltrimethylammonium-exchanged Bentonite for the removal of anionic dyes from aqueous solutions. Indeed, two dyes, i.e. an azo dye CR and a vat dye IC, were chosen as target 
pollutants for the purpose of investigating and understanding the adsorption behavior in terms of adsorption kinetics and equilibrium isotherms. The effects of various parameters, like the amount of surfactant, contact time, adsorbent dosage and initial dyes concentration, were investigated for the removal of dyes from aqueous solutions.

\section{Materials and methods}

\section{Preparation and characteristics of Bentonite}

The natural Bentonite (B) used in this study was acquired from the mining site of Maghnia, a small town in the extreme northwestern region of Algeria. Afterwards, it was purified and then converted to its sodic form, namely sodium Bentonite (Na-B), according to the method published in a previous study.[19] The chemical compositions of B and Na-B are shown in Table 1.

\section{Insert Table 1.}

Furthermore, the specific surface area was determined from the $\mathrm{N}_{2}$ gas adsorption isotherm at 77 K using a Volumetric Analyzer (Nova-1000). Moreover, the cation exchange capacity (CEC) of clay samples was calculated by means of the methylene blue adsorption method [20] and was found to be $37 \mathrm{meq} / 100 \mathrm{~g}$ for dry natural Bentonite and $93 \mathrm{meq} / 100 \mathrm{~g}$ for dry sodic Bentonite. The results obtained indicated that the BET specific surface area increased from $45.04 \mathrm{~m}^{2} \mathrm{~g}^{-1}$ in natural Bentonite (B) to $66.21 \mathrm{~m}^{2} \mathrm{~g}^{-1}$ in sodium Bentonite (Na-B). 


\section{Reagents}

The surfactant hexadecyltrimenthylammonium bromide, denoted as $\operatorname{HDTMA}^{+} \mathrm{Br}^{-}\left(\mathrm{C}_{19} \mathrm{H}_{42} \mathrm{Br}\right.$ $\mathrm{N})$, and the anionic dyes used in this study, with purity $>99 \%$, were purchased from Biochem. The chemical structures and properties of these dyes are clearly depicted in Table 2.

\section{Insert Table 2.}

\section{Preparation and characterization of hybrid-Bentonites}

HDTMA-intercalated Bentonite samples were prepared by intercalation of the ammonium cation into the $\mathrm{Na}-\mathrm{B}$ suspension (5\% clay in water $(\mathrm{w} / \mathrm{w})$ ), based on a previously described procedure [21] which consists of using amounts of HDTMA corresponding to 50, 100 and $200 \%$ of the cation exchange capacity of Na-B; these amounts were next dissolved in $500 \mathrm{~mL}$ of distilled water and the resulting mixtures were then added to $25 \mathrm{~g} \mathrm{Na}-\mathrm{B}$. The admixture was first agitated for $24 \mathrm{~h}$ at room temperature and then centrifuged at $3000 \mathrm{rpm}$ for $15 \mathrm{~min}$. Afterwards, the suspension obtained was filtered, washed several times with distilled water (until a negative bromide test was obtained with $0.1 \mathrm{M}$ of $\mathrm{AgNO}_{3}$ ) and then dried at $70^{\circ} \mathrm{C}$, for a period of $24 \mathrm{~h}$. The materials obtained were designated as 50HDTMA-B, 100HDTMA-B and 200HDTMA-B. The hybrid-Bentonite samples were compared with sodium Bentonite by means of X-ray diffraction (XRD), Fourier transform infrared (FTIR) spectroscopy and Thermogravimetric analyses (TGA). The infrared spectra of clay samples were recorded within the wavenumber range extending from 500 to $4000 \mathrm{~cm}^{-1}$ using a Perkin Elmer FT-IR Spectrophotometer. Moreover, the X-ray diffraction measurements were performed on a Philips $\mathrm{X}$-Pert diffractometer using Ni-filtered $\mathrm{Cu} \mathrm{Ka}$ radiation. 


\section{Adsorption experiments}

The adsorption study was conducted on synthetic wastewater containing Congo red or indigo carmine dyes. An aqueous solution was prepared by dissolving dyes in deionizer water to the desired concentration. With regard to the kinetic study, each experiment was carried out in a $100 \mathrm{~mL}$ Erlenmeyer flask containing $25 \mathrm{~mL}$ of anionic dye solution $\left(50 \mathrm{mg} \mathrm{L}^{-1}\right)$ and $25 \mathrm{mg}$ of adsorbent at natural $\mathrm{pH} 6.6$; the mixture was then subjected to stirring at the speed of $250 \mathrm{rpm}$. Afterwards, the samples were withdrawn from time to time, up to $180 \mathrm{~min}$, and aliquots were taken from theses samples and centrifuged at $3000 \mathrm{rpm}$. The concentration of dye in the supernatant was quantified by the Analytik Jena (SPECORD210) UV-vis spectrophotometer at $\lambda_{\max }$ and was subtracted from the initial concentration in order to determine the amounts of dye adsorbed in each case. The amount adsorbed per mass unit of adsorbent at time $t\left(q_{t}\right)$, the amount adsorbed per mass unit of adsorbent at equilibrium $\left(q_{\mathrm{e}}\right)$ and the adsorption yield $(Y)$ were calculated using the following expressions:

$$
\begin{aligned}
& q_{t}=\left(C_{0}-C_{t}\right) \frac{V}{m} \\
& q_{e}=\left(C_{0}-C_{e}\right) \frac{V}{m} \\
& Y(\%)=\left(1-\frac{C_{t}}{C_{0}}\right) 100
\end{aligned}
$$

Note that $C_{0}$ and $C_{\mathrm{e}}$ are the initial and equilibrium dye concentrations $\left(\mathrm{mg} \mathrm{L}^{-1}\right)$, respectively; $C_{t}$ is the concentration of dye within the aqueous solutions at time $t\left(\mathrm{mg} \mathrm{L}^{-1}\right), q_{t}$ is the amount of dye adsorbed per mass unit of adsorbent at time $t\left(\mathrm{mg} \mathrm{g}^{-1}\right), V$ is the volume of the aqueous solution ( $\mathrm{L}$ ) and $\mathrm{m}$ is the amount of adsorbent $(\mathrm{g})$. Furthermore, the adsorption isotherms were obtained at $(20 \pm 2){ }^{\circ} \mathrm{C}$ by mixing $25 \mathrm{mg}$ of 100 HDTMA-B with $25 \mathrm{~mL}$ of dye solution $(\mathrm{m} / \mathrm{v}=$ $\left.1 \mathrm{~g} \mathrm{~L}^{-1}\right)$ at various initial concentrations $\left(20-500 \mathrm{mg} \mathrm{L}^{-1}\right)$ under continuous and vigorous stirring (250 rpm). The contact time was set to $60 \mathrm{~min}$ (equilibrium time), time beyond which no significant variation in dye concentration was observed. The amount of dye adsorbed was determined after that time. The effect of the solid/solution ratio $(\mathrm{m} / \mathrm{v})$ on the amount of adsorbed 
dye was investigated both on Na-B and 100HDTMA-B, for a constant initial concentration of dye $\left(\mathrm{C}_{0}=50 \mathrm{mg} \mathrm{L}^{-1}, \mathrm{pH}=6.6\right)$, while the $(\mathrm{m} / \mathrm{v})$ ratio was varied within the range extending from 0.1 to $2 \mathrm{~g} \mathrm{~L}^{-1}$.

\section{Results and discussion}

\section{Characterization of adsorbents}

The FTIR spectra of the adsorbent samples are illustrated in Figure 1. The characteristic absorption bands of the clay phase are those corresponding to Si-O, Si-O-M, M-O-H where M stands for $\mathrm{Al}, \mathrm{Fe}$ and $\mathrm{Mg}$. These chemical elements are found between the anions and cations located in the octahedral and tetrahedral sheets with a large number of $\mathrm{OH}$ groups.[19]

It should also be mentioned that the appearance of bands attributed to the surfactants in the modified clays is in the range of $2849-2914 \mathrm{~cm}^{-1}$ corresponding to the anti-symmetrical and symmetrical stretching vibration modes of the $\mathrm{CH}$ bonds in a $\mathrm{CH}_{2}$ or $\mathrm{CH}_{3}$ environment.[22] In addition, the deformation vibration of $\mathrm{C}-\mathrm{H}$ bond was observed at $1475 \mathrm{~cm}^{-1}$. It is important to note that the intensity of $\mathrm{C}-\mathrm{H}$ bands in modified clays increased as the amount of surfactant increased. The intense absorption band at around $1472 \mathrm{~cm}^{-1}$ can be associated to the $\mathrm{C}-\mathrm{H}$ symmetric bending of ammonium groups $\left(\mathrm{N}^{+}-\mathrm{CH}_{3}\right)$ from the HDTMA. These bands are commonly found in hybrid-clays containing alkylamine surfactants.[21]. Furthermore, the characteristic stretching vibration bond of isolated hydroxyl groups of $\mathrm{Si}-\mathrm{OH}$ is observed at $3623 \mathrm{~cm}^{-1}$, however, the appearance of the band between 3540 and $3200 \mathrm{~cm}^{-1}$ is attributed to the valence vibrations of adjacent and geminy polymeric hydroxyl groups. As can be observed from the spectra of unmodified and modified Bentonite that the region between 3650 and 3200 $\mathrm{cm}^{-1}$ which characterize a different group of $\mathrm{OH}$ is still unchanged which means probably that the most amount of surfactant is intercalated into basal space of Bentonite. This evidence is supported by the XRD results. 
In addition, the deformation $\mathrm{O}-\mathrm{H}$ band of the adsorbed water molecules is attributed to 1630 $\mathrm{cm}^{-1}$. It is wise observed that this band decreases when the surfactant increase this phenomenon is in accordance with the hydrophobic character. Because it is widely known that the hydrophobic character increase when the amount of surfactant increase and hence the deformation band of $\mathrm{OH}$ physisorbed decreases. This statement is in agreement with that given by Zaghouane et al.[23]

\section{Insert Figure 1.}

In order to determine the influence of the surfactant loading on the weight loss, some Bentonite samples were characterized by thermal gravimetric analysis (TGA) and derivative thermogravimetry (DTG). For this, approximately $20 \mathrm{mg}$ of a sample were heated from 20 to $1000{ }^{\circ} \mathrm{C}$ at a heating rate of $20{ }^{\circ} \mathrm{C} / \mathrm{min}$, under nitrogen atmosphere. The TGA and DTG data of sodium Bentonite (Na-B) and hybrid- Bentonites are plotted in Figure 2. From the TGA curve of Na-B, two major weight loss stages were observed. The first one was at $99.26{ }^{\circ} \mathrm{C}(6.2 \%)$, due to the dehydration of the materials; it is attributed to the interlayer adsorption of water. [24] However, the other weight loss stage was at $645.50{ }^{\circ} \mathrm{C}(2.2 \%)$ and is attributed to the dehydroxylation of montmorillonite.[25] With regard to the surfactant-modified Bentonites, the evolution of weight loss can be divided into three steps. The first one is below $200{ }^{\circ} \mathrm{C}$; the weight loss is assigned to the dehydration of physically adsorbed water. It is interesting to note from the plots that HDTMA-B shows a lower weight loss than Na-B, which indicates that less free water exists in hybrid-Bentonites; this means that the surface energy of clay was reduced by the adsorbed HDTMA, and the hydrophilic silicate surface was converted into a hydrophobic silicate surface.[26] The second step is within the temperature range $200-500{ }^{\circ} \mathrm{C}$; it corresponds to the decomposition of the intercalated surfactant. In this interval, the thermal gravimetric analysis (TGA) curves show an increase in the weight loss as the amount of alkyl ammonium loading grows, i.e. 5.0\% (50HDTMA-B), 16.5\% (100HDTMA-B) and 30.1\% (200HDTMA- 
B). In contrast, the DTG curves indicate that the temperature peaks resulting from thermal decomposition decreased from $296.74{ }^{\circ} \mathrm{C}$ for 50 HDTMA-B to $276.84{ }^{\circ} \mathrm{C}$ for 200 HDTMA-B, as can be seen in Figure 2. Similar observations have been reported in previous studies using various surfactant-modified clays. [26, 27] The third step concerns the temperature range from $550{ }^{\circ} \mathrm{C}$ to $750^{\circ} \mathrm{C}$ where the weight loss is essentially attributed to the dehydroxylation of $\mathrm{OH}$ units.

\section{Insert Figure 2.}

The XRD patterns of sodic Bentonite and HDTMA-modified Bentonite are clearly illustrated in Figure 3. The interlayer distance $\left(\mathrm{d}_{001}\right)$ was calculated from the measured diffraction angle (20) value using Bragg's equation (inset in Figure 3). The interlayer expansion of hybridBentonite can be clearly observed as the amount of hexadecyltrimethylammonium surfactant increases. When the surfactant loading is around $50 \%$ of CEC, the $\mathrm{d}_{001}$ spacing is approximately equal to $1.79 \mathrm{~nm}$. This augmentation was assigned to the lateral bilayer of the $\mathrm{HDTMA}^{+}$cation arrangement model.[28] The interlayer spacing in the 100HDTMA-B sample reaches the maximum value of $2.99 \mathrm{~nm}$, with a shoulder at $1.98 \mathrm{~nm}$, when the surfactant loading is $100 \%$ of CEC. This finding confirms the coexistence of pseudotrimolecular and paraffin-type arrangements.[29] However, the $\mathrm{d}_{001}$ diffraction peak of the 200HDTMA-B sample disappeared, which suggests that Bentonite is fully exfoliated.

\section{Insert Figure 3.}




\section{Adsorption kinetics}

The use of sodic Bentonite and synthesized hybrid-Bentonite in the adsorption of anionic dyes $\mathrm{CR}$ and IC taken as model pollutants was investigated. Figure 4 indicates that the adsorption yield of dyes on Bentonite samples increased as contact time augmented to reach the highest sorption percent after $60 \mathrm{~min}$. It is worth mentioning that the adsorption process of CR and IC dyes on HDTMA-modified Bentonite was relatively fast at the beginning. However, the curves corresponding to the IC/Na-B, CR/Na-B and IC/50-HDTMA-B systems indicate that the adsorption operation started slowing down until equilibrium. Moreover, the adsorption of IC on 200HDTMA-B increased with increasing contact time to reach a maximum adsorption percentage after $10 \mathrm{~min}$, followed by a decrease until reaching equilibrium after $120 \mathrm{~min}$ (Fig. $4 b)$.

\section{Insert Figure 4.}

Figure 5 displays the effect of the amounts of HDTMA on the adsorption efficiency of CR and IC onto Bentonite samples, at equilibrium. This same figure indicates that the percentage of anionic dye sorption gradually increased as the ammonium surfactant loading went up from $0 \%$ CEC to $100 \%$ CEC. However, the adsorption yield decreased when the surfactant loading reached 200\% CEC. For example, the maximum yields of CR adsorption on various Bentonite adsorbents, namely Na-B, 50HDTMA-B, 100HDTMA-B and 200HDTMA-B, were 14.5, 86.2, 98.7 and $80.5 \%$, respectively. This is mainly due to the fact that increasing the amount of HDTMA causes them to densely pack between the layers. Therefore, it may be said that the CR and IC dyes cannot penetrate into the interlayer space with high packing density, which leads to lower removal efficiency.[30] Comparison of CR with IC dyes suggests that the removal efficiency for CR is significantly larger than that for IC under the same modifier loadings.

\section{Insert Figure 5.}


In order to understand the dynamics of adsorption, the experimental data of the kinetic study were examined using the pseudo-first-order and the pseudo-second-order adsorption models. The pseudo-first-order kinetic model, also described by the Lagergren kinetic equation, is widely employed to understand the kinetic behavior of the system.[31] It is generally expressed by the following equation [32]:

$\log \left(q_{e}-q_{t}\right)=\log q_{e}-\left(\frac{k_{1}}{2.303}\right) t$

The pseudo-second-order kinetic model is given by the equation [33]:

$\frac{t}{q_{t}}=\frac{1}{k_{2} q_{e}^{2}}+\frac{1}{q_{e}} t$

Where $q_{e}$ and $q_{t}\left(\mathrm{mg} \mathrm{g}^{-1}\right)$ are the amounts of dye sorbed at equilibrium and at time $t$, respectively; $k_{1}$ and $k_{2}$ are the equilibrium rate constants of the pseudo-first-order model $\left(\mathrm{min}^{-1}\right)$ and the pseudo-second-order model $\left(\mathrm{g} \mathrm{mg}^{-1} \mathrm{~min}^{-1}\right)$, respectively.

\section{Insert Figure 6.}

\section{Insert Table 3.}

The fitting curves of the kinetic model to the experimental data are shown in Figure 6, and the results are summarized in Table 3 (the pseudo-first-order fitting plots are not presented here). It can clearly be seen that the correlation coefficients $\left(\mathrm{R}^{2}\right)$ are close to unity, and the experimental values of the adsorption capacity $\left(q_{e, \exp }\right)$ agree well with the calculated values $\left(q_{e, c a l}\right)$ in the pseudo-second-order model. This implies that the adsorption kinetics of anionic dyes onto Na-B and surfactant-modified Bentonite obeys the pseudo-second-order model. Similar results have been reported by T.S. Anirudhan et al.[34] in the adsorption of basic dyes such as methylene blue, crystal violet and Rhodamine B, on Hexadecyltrimethylammonium chloride-modified Bentonite clay. It is also worth recalling that Daimei Chen et al.[35] conducted a study on the removal of methyl orange using anion-cationic surfactant-modified Bentonite, and Adarsh et al[36] examined the adsorption of Remazol Brilliant Blue R on organo-attapulgite and hybrid-Bentonite. Moreover, several investigators [18, 37] indicated that 
the pseudo-second-order model is based on the assumption that chemisorption may be the ratelimiting step, involving covalent or ionic bonds between the adsorbent and the adsorbate. The amount of $\mathrm{CR}$ dye removed at equilibrium increased in the following order: Na-B < 200HDTMA-B < 50HDTMA-B < 100HDTMA-B. It was observed that the amounts of dye adsorbed are not proportional to the rates of surfactant intercalation into Bentonite. This can certainly be explained by the fact that the interaction between the adsorbent and dyes is strongly influenced by the interaction between silica and alumina sheets in montmorillonite in spite of the hydrophobic sites created by the intercalated HDTMA. In the case of 100HDTMA-B, when the amount of intercalated surfactant was $100 \%$ CEC, the interaction between the Bentonite surface and ammonium cations was significantly high, which allowed adsorbing a large amount of dyes. On the other hand, when a large quantity of HDTMA was added, the alkyl chains played a predominant role on clay surface and the interactions between the hydrocarbon chains of the surfactant were relatively strong, which led to a weak interaction between the adsorbate and the adsorbent surface. However, with further addition of surfactant, the contribution of hydrocarbon chains to the surface was not significant, given the porous structure of montmorillonite. [21] This was inferred from the adsorption capacity of 200HDTMA-B which was lower than that of 100HDTMA-B. This result is similar to that found by other authors on the behavior of hexadecyltrimethylammonium bromide-modified Bentonite with respect to uranium [38] and also on the adsorption of aniline on hybrid-Bentonite modified with bispyridinium dibromides. [39] These same authors indicated that the decrease in adsorption capacity with the increase in cationic surfactant loading is due to the steric hindrance caused by the surfactant packing density.

Furthermore, the amounts of CR and IC dyes removed by different types of adsorbents at equilibrium ( $\mathrm{q}_{\mathrm{e}}$ ), according to the pseudo-second-order model, are summarized in Table 4. Note that at $50 \mathrm{mg} \mathrm{L}^{-1}$ of initial dye concentration, $49.3 \mathrm{mg} \mathrm{g}^{-1}$ of $\mathrm{CR}$ and $45.5 \mathrm{mg} \mathrm{g}^{-1}$ of IC were 
removed by the adsorbent 100 HDTMA-B, when the ratio $(\mathrm{m} / \mathrm{v})$ is equal to unity and $\mathrm{pH}=6.6$. In comparison with other materials, the amounts of anionic dyes adsorbed onto the adsorbents considered in this study at equilibrium are lower than those sorbed on nanocomposites, but are higher than those removed by cethyltrimethylammonium bromide-modified kaolin, surfactant modified pumice, metal hydroxides sludge and $\mathrm{CaCO}_{3}$-loaded cellulose aerogel. This can certainly be attributed to the fact that the adsorbents used in this paper have a larger adsorption capacity than many reported adsorbents.

\section{Insert Table 4.}

In this case, the $\mathrm{CR}$ and IC molecules were probably transported by the adsorbent particles following the intra-particle diffusion process because of the porosity of organo-clays. For the purpose of explaining the adsorption mechanism of both CR and IC dyes, it was decided to use the Weber and Morris equation given below [40]:

$q_{t}=k_{i d} t^{0.5}+I$

This equation originates from Fick's second law. Note that $k_{i d}$ is the intra-particle diffusion rate constant $\left(\mathrm{mg} \mathrm{g}^{-1} \min ^{-0.5}\right)$ and $\mathrm{I}$ is the intercept. The values recorded for I help to make an approximation of the boundary layer thickness. It is worth noting that the larger the value of I, the greater the boundary layer effect. In addition, the deviation of the straight line from the origin may be attributed to the weight transfer difference between the initial and final adsorption stages.[41] The intra-particle diffusion model suggests that the plot of $\mathrm{q}_{\mathrm{t}}$ versus $\mathrm{t}^{0.5}$ should be linear. In theory, these types of plots may present a multilinearity, indicating that two or more stages are taking place[42]. Figure 7 displays the amount of anionic dyes adsorbed per unit mass of adsorbent, $\mathrm{q}_{\mathrm{t}}$ versus $\mathrm{t}^{0.5}$ for the adsorption of CR and IC dyes. Since the graph does not pass through the origin, then it may be concluded there is some degree of boundary layer control. Therefore, the intra-particle diffusion is not the only rate controlling step, but other processes can also control the rate of adsorption of anionic dyes.[43] Indeed, the curves show 
that two steps occur during the adsorption process. The first stage is a gradual adsorption, where the diffusion of dye molecules on the surface of the adsorbents can be rate-controlling. Final equilibrium is reached during the second stage. A linear equation was fitted to the experimental data obtained in the first 20 minutes. The values obtained for $\mathrm{k}_{\mathrm{id}}, \mathrm{I}$, and $\mathrm{R}^{2}$ are given in Table 3, which indicates that the adsorption rate constant $\mathrm{k}_{\mathrm{id}}$ onto HDTMA-modified Bentonite was far larger than that onto Na-B. Therefore, the diffusion of CR or IC dyes had to be faster with the increase in cationic surfactant loading from 0 to $100 \% \mathrm{CEC}$, which suggests that the adsorption of anionic dyes is faster with increased adsorbent organo-philicity [44] However, dye diffusion was slower in the case of 200HDTMA-B. In addition, the diffusion rate for CR dye at the surface of the material or across the inter-lamellar space was faster than for the IC dye.

\section{Insert Figure 7.}

\section{Effect of adsorbent dosage (solid/solution ratio)}

The effect of the solid/solution ratio on the adsorption efficiency of CR and IC dyes both on Na-B and 100HDTMA-B is shown in Figure 8. It can be observed that the percentage removal of CR dye increased from 0.8 to $21.9 \%$ and from 53.4 to $99.1 \%$ when the dosages of Na-B and 100HDTMA-B were increased from 0.1 to $2 \mathrm{~g} \mathrm{~L}^{-1}$, respectively, as can be seen in Figure $8 \mathrm{a}$. These results clearly demonstrate the improved CR adsorption efficiency of alkyl ammonium surfactant-modified Bentonite. Therefore, it may be stated that $1 \mathrm{gL}^{-1}$ of surfactant-modified Bentonite was the optimum adsorbent dosage which represents the beginning of the saturation process, because higher amounts of adsorbent did not increase appreciably the CR adsorption. Figure 8b suggests that the percentage removal of IC dye increased from 14 to $94 \%$ when the HDTMA-B dosage augmented from $0.1 \mathrm{~g} \mathrm{~L}^{-1}$ to $0.75 \mathrm{~g} \mathrm{~L}^{-1}$, respectively. Beyond this dosage value, the adsorption efficiency dropped to $91 \%$ and remained unchangeable. As for Na-B, low 
yields were obtained; the maximum was observed for a solid/solution ratio of $0.1 \mathrm{~g} \mathrm{~L}^{-1}(11.7$ $\%$ ). Afterwards, this yield went down to $5.9 \%$ when the adsorbent dosage increased to $2 \mathrm{~g} \mathrm{~L}^{-1}$. The increase in the anionic dye removal indicates that the number of sorption sites on the adsorbent surface increased; this also suggests that more active binding sites become widely available as the adsorbent dosage grows.[45] These findings are similar to those previously reported by other authors ${ }^{[[46]]}$ who indicated that at a higher adsorbent dosage, a portion of the solid surface remains uncovered due to the aggregation of the adsorbent particles.

\section{Insert Figure 8.}

\section{Effect of initial concentration}

Figure 9 indicates that any increase in the initial concentration of the organic pollutant, within the range from 20 to $500 \mathrm{mg} \mathrm{L}^{-1}$, induces an increase in the adsorption capacity from 19.7 to $273.1 \mathrm{mg} \mathrm{g}^{-1}$ for CR dye and from 14.2 to $240 \mathrm{mg} \mathrm{g}^{-1}$ for IC dye, respectively. The rise in the adsorption capacity as the initial concentration goes up can be explained by the growing driving force of the anionic dye to the active sites on the adsorbent. These findings are qualitatively in good agreement with those reported by Manjot et al.[47] and Gondzalez-Pradas et al.[48]. On the other hand, some histograms suggest that increasing the initial IC concentration (Fig.9 b) leads to higher adsorption efficiency to ultimately reach a maximum of $96 \%$ at $100 \mathrm{mg} \mathrm{L}^{-1}$; beyond this value, the removal efficiency gradually decreases. In addition, Figure 9a clearly shows that the yield is highest (99\%) for initial CR concentrations ranging between 20 and 100 $\mathrm{mg} \mathrm{L} \mathrm{L}^{-1}$. Beyond this concentration, the removal efficiency gradually decreases to reach a percentage yield of $54.5 \%$ at an initial concentration of $500 \mathrm{mg} \mathrm{L}^{-1}$.

\section{Insert Figure 9.}

\section{Adsorption isotherm study}


The adsorption isotherms were used to understand the adsorption interaction and the design efficient adsorption systems. Most of the adsorption data show a good fit to the Langmuir and Freundlich models. The obtained experimental data are commonly well fitted to the Langmuir (Equation 7) [49] and Freundlich (Equation 8) [50] models:

$\frac{1}{q_{e}}=\frac{1}{q_{m}}+\frac{1}{b q_{m}} \frac{1}{C_{e}}$

$\ln q_{e}=\ln K_{F}+\frac{1}{n} \ln C_{e}$

where the constants $K_{F}, n$ are for the Freundlich model and $b$ for the Langmuir model; $q_{m}$ (mg $\left.\mathrm{g}^{-1}\right)$ is the maximum adsorption capacity for monolayer surface coverage.

\section{Insert Figure 10.}

The experimental data for the CR and IC adsorption isotherms are presented in Figure 10. According to Giles classification,[51] the HDTMA-hybrid Bentonite exhibits an L-type isotherm, corresponding to the formation of a dye monolayer on the surface of the adsorbent. The fitted curves of Freundlich and Langmuir models are depicted in Figure 11. The parameters predicted by the two different models are summarized in Table 5. In general, these parameters exhibited a good fit to the linear adjustment, but the correlation coefficient was better adjusted using the Langmuir model.

\section{Insert Figure 11.}

\section{Insert Table 5.}

The favorability and feasibility of the adsorption process can be determined by the dimensionless equilibrium parameter or adsorption intensity of Hall $\left(\mathrm{R}_{\mathrm{L}}\right)$ in the analysis of data using the Langmuir isotherm. This parameter is given by the following equation [52]:

$R_{L}=\frac{1}{1+b C_{0}}$

The quantity $\mathrm{R}_{\mathrm{L}}$ indicates whether the isotherm is irreversible $\left(\mathrm{R}_{\mathrm{L}}=0\right)$, favorable $\left(0<\mathrm{R}_{\mathrm{L}}<1\right)$, linear $\left(R_{L}=1\right)$ or unfavorable $\left(R_{L}>1\right)$. Close examination of the graph obtained by plotting $R_{L}$ 
vs. $\mathrm{C}_{0}$, at $20^{\circ} \mathrm{C}$ (inset in Fig. 10), shows that the $\mathrm{R}_{\mathrm{L}}$ values are within the range from 0 and 1 , and approached the value zero as $\mathrm{C}_{0}$ increased, suggesting the favorable adsorption of $\mathrm{CR}$ and IC dyes onto HDTMA-modified Bentonite.

The maximum adsorption capacities $\left(\mathrm{q}_{\mathrm{m}}\right)$ for the sorption of CR and IC onto HDTMA-modified Bentonite were found equal to 292.4 and $289 \mathrm{mg} \mathrm{g}^{-1}$, respectively. Note that these values are significantly higher than those of other adsorbents. For example, this value was equal to 71.82 and $55.5 \mathrm{mg} \mathrm{g}^{-1}$ for IC dye for chitosan [53] and mesoporous LDH nanoparticles [54], respectively. In the case of CR, Ghorai et al.[55] and Sagar et al.[56] reported the values of $209.20 \mathrm{mg} \mathrm{g}^{-1}$ for Xanthan gum-graft-poly (acrylamide)/ $\mathrm{SiO}_{2}$ nanocomposite and $233.24 \mathrm{mg} \mathrm{g}^{-}$ ${ }^{1}$ for g-GG/SiO 2 nanocomposite, respectively. 


\section{Conclusion}

In this work, the hybrid-Bentonite were prepared with the cationic surfactant hexadecyltrimethylammonium bromide for the removal of diazo and indigo dyes from aqueous solutions. The intercalation of the organic molecule in the interlayer space of sodic Bentonite was confirmed either by FTIR, DTA-TG or XRD. The adsorption mechanism was found to be strongly dependent on the amount of modifier, contact time, adsorbent dosage and initial anionic dye concentration. The adsorption capacities of the hybrid- Bentonite for anionic dyes were much higher than that of sodic Bentonite. The removal efficiency of CR was larger than that of IC on HDTMA-modified Bentonite for the same modifier loadings. The experimental results show that Bentonite functionalized with the surfactant HDTMA with a quantity corresponding to $100 \%$ of CEC has a high affinity for anionic dyes. The pseudo-second-order model provided the best correlation of the experimental data. The results from the Weber and Morris model revealed that the intraparticle diffusion is not the only process controlling the CR and IC adsorption on Na-B and HDTMA-modified Bentonite. The equilibrium analysis showed that the Langmuir isotherm fitted better the adsorption data, and the maximum adsorption capacities were $292.4 \mathrm{mg} \mathrm{g}^{-1}$ for $\mathrm{CR}$ and $289.0 \mathrm{mg} \mathrm{g}^{-1}$ for $\mathrm{IC}$, at $20{ }^{\circ} \mathrm{C}$ and $\mathrm{pH}=6.6$. These findings indicate that the organic modification of Bentonite with a cationic surfactant, like HDTMA, is an economical method for the enhancement of the adsorption properties. 


\section{Acknowledgments}

The authors gratefully acknowledge the_financial support from the Thematic Agency for Research in Science and Technology Algeria. 


\section{References}

[1] A. Welham, "The theory of dyeing(and the secret of life)," Journal of the Society of Dyers and Colourists, vol. 116, pp. 140-3, (2000).

[2] P. C. Vandevivere, R. Bianchi, and W. Verstraete, "Treatment and reuse of wastewater from the textile wet-processing industry: Review of emerging technologies," Journal of Chemical Technology \& Biotechnology: International Research in Process, Environmental AND Clean Technology, vol. 72, pp. 289-302, (1998).

[3] C.-H. Chang, C.-C. Lin, Y. Kawata, M. Hattori, and T. Namba, "Prenylated xanthones from Cudrania cochinchinensis," Phytochemistry, vol. 28, pp. 2823-2826, (1989).

[4] M. S. Mahmoud, M. K. Mostafa, S. A. Mohamed, N. A. Sobhy, and M. Nasr, "Bioremediation of red azo dye from aqueous solutions by Aspergillus niger strain isolated from textile wastewater," Journal of environmental chemical engineering, vol. 5, pp. 547-554, (2017).

[5] Y. Hu, X. Chen, Z. Liu, G. Wang, and S. Liao, "Activated carbon doped with biogenic manganese oxides for the removal of indigo carmine," Journal of environmental management, vol. 166, pp. 512-518, (2016).

[6] R. Combes and R. Haveland-Smith, "A review of the genotoxicity of food, drug and cosmetic colours and other azo, triphenylmethane and xanthene dyes," Mutation Research/Reviews in genetic toxicology, vol. 98, pp. 101-243, (1982).

[7] M. A. Brown and S. C. De Vito, "Predicting azo dye toxicity," Critical reviews in environmental science and technology, vol. 23, pp. 249-324, (1993).

[8] C.-Z. Liang, S.-P. Sun, F.-Y. Li, Y.-K. Ong, and T.-S. Chung, "Treatment of highly concentrated wastewater containing multiple synthetic dyes by a combined process of coagulation/flocculation and nanofiltration," Journal of Membrane Science, vol. 469, pp. 306-315,( 2014).

[9] J. Fan, X. Hu, Z. Xie, K. Zhang, and J. Wang, "Photocatalytic degradation of azo dye by novel Bi-based photocatalyst Bi4TaO8I under visible-light irradiation," Chemical Engineering Journal, vol. 179, pp. 44-51, (2012).

[10] M. Mitchell, W. R. Ernst, G. R. Lightsey, E. T. Rasmussen, and P. Bagherzadeh, "Adsorption of textile dyes by activated carbon produced from agricultural, municipal and industrial wastes," Bulletin of environmental contamination and toxicology, vol. 19, pp. 307-311, (1978).

[11] D. F. Brito, E. C. da Silva Filho, M. G. Fonseca, and M. Jaber, "Organophilic bentonites obtained by microwave heating as adsorbents for anionic dyes," Journal of environmental chemical engineering, vol. 6, pp. 7080-7090, (2018).

[12] A. S. Özcan, B. Erdem, and A. Özcan, "Adsorption of Acid Blue 193 from aqueous solutions onto BTMA-bentonite," Colloids and Surfaces A: Physicochemical and Engineering Aspects, vol. 266, pp. 73-81, (2005).

[13] J. A. Smith, P. R. Jaffe, and C. T. Chiou, "Effect of ten quaternary ammonium cations on tetrachloromethane sorption to clay from water," Environmental Science \& Technology, vol. 24, pp. 1167-1172, (1990).

[14] G. Sheng, S. Xu, and S. A. Boyd, "Surface heterogeneity of trimethylphenylammoniumsmectite as revealed by adsorption of aromatic hydrocarbons from water," Clays and clay minerals, vol. 45, pp. 659-669,(1997).

[15] J. Ma, B. Cui, J. Dai, and D. Li, "Mechanism of adsorption of anionic dye from aqueous solutions onto organobentonite," Journal of Hazardous Materials, vol. 186, pp. 1758-1765, (2011).

[16] D. Shen, J. Fan, W. Zhou, B. Gao, Q. Yue, and Q. Kang, "Adsorption kinetics and isotherm of anionic dyes onto organo-bentonite from single and multisolute systems," Journal of Hazardous Materials, vol. 172, pp. 99-107, (2009). 
[17] C. Xia, Y. Jing, Y. Jia, D. Yue, J. Ma, and X. Yin, "Adsorption properties of congo red from aqueous solution on modified hectorite: kinetic and thermodynamic studies," Desalination, vol. 265, pp. 81-87, 2011.

[18] L. Wang and A. Wang, "Adsorption properties of Congo Red from aqueous solution onto surfactant-modified montmorillonite," Journal of Hazardous Materials, vol. 160, pp. 173180, 2008.

[19] B. Makhoukhi, M. Djab, and M. A. Didi, "Adsorption of Telon dyes onto bis-imidazolium modified bentonite in aqueous solutions," Journal of environmental chemical engineering, vol. 3, pp. 1384-1392, 2015.

[20] P. B. Arab, T. P. Araújo, and O. J. Pejon, "Identification of clay minerals in mixtures subjected to differential thermal and thermogravimetry analyses and methylene blue adsorption tests," Applied Clay Science, vol. 114, pp. 133-140, 2015.

[21] I. Fatimah and T. Huda, "Preparation of cetyltrimethylammonium intercalated Indonesian montmorillonite for adsorption of toluene," Applied Clay Science, vol. 74, pp. 115-120, 2013.

[22] L.-g. Yan, L.-I. Qin, H.-q. Yu, S. Li, R.-r. Shan, and B. Du, "Adsorption of acid dyes from aqueous solution by СТMAВ modified bentonite: kinetic and isotherm modeling," Journal of Molecular Liquids, vol. 211, pp. 1074-1081, 2015.

[23] H. Zaghouane-Boudiaf, M. Boutahala, S. Sahnoun, C. Tiar, and F. Gomri, "Adsorption characteristics, isotherm, kinetics, and diffusion of modified natural bentonite for removing the 2, 4, 5-trichlorophenol," Applied Clay Science, vol. 90, pp. 81-87, 2014.

[24] F. Dellisanti, V. Minguzzi, and G. Valdrè, "Thermal and structural properties of Ca-rich montmorillonite mechanically deformed by compaction and shear," Applied Clay Science, vol. 31, pp. 282-289, 2006.

[25] I. Lapides, M. Borisover, and S. Yariv, "Thermal analyis of hexadecyltrimethylammoniummontmorillonites: Part 1. Thermogravimetry, carbon and hydrogen analysis and thermo-IR spectroscopy analysis," Journal of thermal analysis and calorimetry, vol. 105, pp. 921-929, 2011.

[26] S. I. Rathnayake, Y. Xi, R. L. Frost, and G. A. Ayoko, "Structural and thermal properties of inorganic-organic montmorillonite: Implications for their potential environmental applications," Journal of colloid and interface science, vol. 459, pp. 17-28, 2015.

[27] M. E. Parolo, G. R. Pettinari, T. B. Musso, M. P. Sánchez-Izquierdo, and L. G. Fernández, "Characterization of organo-modified bentonite sorbents: the effect of modification conditions on adsorption performance," Applied Surface Science, vol. 320, pp. 356-363, 2014.

[28] W. H. Yu, Q. Q. Ren, D. S. Tong, C. H. Zhou, and H. Wang, "Clean production of CTABmontmorillonite: formation mechanism and swelling behavior in xylene," Applied Clay Science, vol. 97, pp. 222-234, 2014.

[29] Z. Luo, M. Gao, Y. Ye, and S. Yang, "Modification of reduced-charge montmorillonites by a series of Gemini surfactants: Characterization and application in methyl orange removal," Applied Surface Science, vol. 324, pp. 807-816, 2015.

[30] Q. Yang, M. Gao, Z. Luo, and S. Yang, "Enhanced removal of bisphenol A from aqueous solution by organo-montmorillonites modified with novel Gemini pyridinium surfactants containing long alkyl chain," Chemical Engineering Journal, vol. 285, pp. 27-38, 2016.

[31] Y. Ho and G. McKay, "Comparative sorption kinetic studies of dye and aromatic compounds onto fly ash," Journal of Environmental Science \& Health Part A, vol. 34, pp. 1179-1204, 1999.

[32] A. Hosseini-Bandegharaei, M. S. Hosseini, M. Sarw-Ghadi, S. Zowghi, E. Hosseini, and H. Hosseini-Bandegharaei, "Kinetics, equilibrium and thermodynamic study of $\mathrm{Cr}$ (VI) sorption into toluidine blue o-impregnated XAD-7 resin beads and its application for the treatment of wastewaters containing Cr (VI)," Chemical Engineering Journal, vol. 160, pp. 190-198, 2010.

[33] Y.-S. Ho and G. McKay, "The kinetics of sorption of divalent metal ions onto sphagnum moss peat," Water research, vol. 34, pp. 735-742, 2000. 
[34] T. Anirudhan and M. Ramachandran, "Adsorptive removal of basic dyes from aqueous solutions by surfactant modified bentonite clay (organoclay): kinetic and competitive adsorption isotherm," Process Safety and Environmental Protection, vol. 95, pp. 215-225, 2015.

[35] D. Chen, J. Chen, X. Luan, H. Ji, and Z. Xia, "Characterization of anion-cationic surfactants modified montmorillonite and its application for the removal of methyl orange," Chemical Engineering Journal, vol. 171, pp. 1150-1158, 2011.

[36] A. S. Bhatt, P. L. Sakaria, M. Vasudevan, R. R. Pawar, N. Sudheesh, H. C. Bajaj, and H. M. Mody, "Adsorption of an anionic dye from aqueous medium by organoclays: equilibrium modeling, kinetic and thermodynamic exploration," RSC advances, vol. 2, pp. 8663-8671, 2012.

[37] Y.-S. Ho and G. McKay, "Pseudo-second order model for sorption processes," Process biochemistry, vol. 34, pp. 451-465, 1999.

[38] F. Houhoune, D. Nibou, S. Chegrouche, and S. Menacer, "Behaviour of modified hexadecyltrimethylammonium bromide bentonite toward uranium species," Journal of environmental chemical engineering, vol. 4, pp. 3459-3467, 2016.

[39] Z. Gu, M. Gao, Z. Luo, L. Lu, Y. Ye, and Y. Liu, "Bis-pyridinium dibromides modified organobentonite for the removal of aniline from wastewater: A positive role of $\pi-\pi$ polar interaction," Applied Surface Science, vol. 290, pp. 107-115, 2014.

[40] W. J. Weber and J. C. Morris, "Kinetics of adsorption on carbon from solution," Journal of the Sanitary Engineering Division, vol. 89, pp. 31-60, 1963.

[41] C. S. Gulipalli, B. Prasad, and K. L. Wasewar, "Batch study, equilibrium and kinetics of adsorption of selenium using rice husk ash (RHA)," Journal of Engineering Science and Technology, vol. 6, pp. 586-605, 2011.

[42] R.-S. Juang, F.-C. Wu, and R.-L. Tseng, "Mechanism of adsorption of dyes and phenols from water using activated carbons prepared from plum kernels," Journal of colloid and interface science, vol. 227, pp. 437-444, 2000.

[43] G. Crini, H. N. Peindy, F. Gimbert, and C. Robert, "Removal of Cl Basic Green 4 (Malachite Green) from aqueous solutions by adsorption using cyclodextrin-based adsorbent: Kinetic and equilibrium studies," Separation and Purification Technology, vol. 53, pp. 97-110, 2007.

[44] N. Jović-Jovičić, A. D. Milutinović-Nikolić, M. Žunić, Z. Mojović, P. Banković, I. Gržetić, and D. M. Jovanović, "Synergic adsorption of Pb2+ and reactive dye-RB5 on two series of organomodified bentonites," Journal of contaminant hydrology, vol. 150, pp. 1-11, 2013.

[45] T. Vidhyadevi, A. Murugesan, S. D. Kirupha, P. Baskaralingam, L. Ravikumar, and S. Sivanesan, "Adsorption of Congo Red dye over pendent chlorobenzylidine rings present on polythioamide resin: kinetic and equilibrium studies," Separation Science and Technology, vol. 48, pp. 1450-1458, 2013.

[46] M. Laabd, H. A. Ahsaine, A. El Jaouhari, B. Bakiz, M. Bazzaoui, M. Ezahri, A. Albourine, and A. Benlhachemi, "Congo red removal by PANi/Bi2WO6 nanocomposites: kinetic, equilibrium and thermodynamic studies," Journal of environmental chemical engineering, vol. 4, pp. 3096-3105, 2016.

[47] M. Toor and B. Jin, "Adsorption characteristics, isotherm, kinetics, and diffusion of modified natural bentonite for removing diazo dye," Chemical Engineering Journal, vol. 187, pp. 7988, 2012.

[48] E. Gonzalez-Pradas, M. Villafranca-Sanchez, A. Gallego-Campo, D. Urena-Amate, and M. Fernandez-Perez, "Removal of atrazine from aqueous solution by natural and activated bentonite," Journal of environmental quality, vol. 26, pp. 1288-1291, 1997.

[49] I. Langmuir, "The constitution and fundamental properties of solids and liquids. Part I. Solids," Journal of the American chemical society, vol. 38, pp. 2221-2295, 1916.

[50] H. Freundlich, "Over the adsorption in solution," J. Phys. Chem, vol. 57, pp. 1100-1107, 1906.

[51] C. Giles, T. MacEwan, S. Nakhwa, and D. Smith, "786. Studies in adsorption. Part XI. A system of classification of solution adsorption isotherms, and its use in diagnosis of adsorption 
mechanisms and in measurement of specific surface areas of solids," Journal of the Chemical Society (Resumed), pp. 3973-3993, 1960.

[52] K. R. Hall, L. C. Eagleton, A. Acrivos, and T. Vermeulen, "Pore-and solid-diffusion kinetics in fixed-bed adsorption under constant-pattern conditions," Industrial \& Engineering Chemistry Fundamentals, vol. 5, pp. 212-223, 1966.

[53] A. G. Prado, J. D. Torres, E. A. Faria, and S. I. C. Dias, "Comparative adsorption studies of indigo carmine dye on chitin and chitosan," Journal of colloid and interface science, vol. 277, pp. 43-47, 2004.

[54] M. Ahmed and A. Mohamed, "An efficient adsorption of indigo carmine dye from aqueous solution on mesoporous $\mathrm{Mg} / \mathrm{Fe}$ layered double hydroxide nanoparticles prepared by controlled sol-gel route," Chemosphere, vol. 174, pp. 280-288, 2017.

[55] S. Ghorai, A. K. Sarkar, A. B. Panda, and S. Pal, "Effective removal of Congo red dye from aqueous solution using modified xanthan gum/silica hybrid nanocomposite as adsorbent," Bioresource technology, vol. 144, pp. 485-491, 2013.

[56] S. Pal, A. S. Patra, S. Ghorai, A. K. Sarkar, V. Mahato, S. Sarkar, and R. Singh, "Efficient and rapid adsorption characteristics of templating modified guar gum and silica nanocomposite toward removal of toxic reactive blue and Congo red dyes," Bioresource technology, vol. 191, pp. 291-299, 2015.

[57] F. Geyikçi, "Factorial design analysis for adsorption of Indigo Carmine onto MontmorilloniteEvaluation of the kinetics and equilibrium data," Progress in Organic Coatings, vol. 98, pp. 28-34, 2016.

[58] V. Vimonses, S. Lei, B. Jin, C. W. Chow, and C. Saint, "Kinetic study and equilibrium isotherm analysis of Congo Red adsorption by clay materials," Chemical Engineering Journal, vol. 148, pp. 354-364, 2009.

[59] H. Chen and J. Zhao, "Adsorption study for removal of Congo red anionic dye using organoattapulgite," Adsorption, vol. 15, pp. 381-389, 2009.

[60] A. Ausavasukhi, C. Kampoosaen, and O. Kengnok, "Adsorption characteristics of Congo red on carbonized leonardite," Journal of Cleaner Production, vol. 134, pp. 506-514, 2016.

[61] H. Shayesteh, A. Rahbar-Kelishami, and R. Norouzbeigi, "Evaluation of natural and cationic surfactant modified pumice for congo red removal in batch mode: Kinetic, equilibrium, and thermodynamic studies," Journal of Molecular Liquids, vol. 221, pp. 1-11, 2016.

[62] M. Attallah, I. Ahmed, and M. M. Hamed, "Treatment of industrial wastewater containing Congo Red and Naphthol Green B using low-cost adsorbent," Environmental Science and Pollution Research, vol. 20, pp. 1106-1116, 2013.

[63] K. Y. Chong, C. H. Chia, S. Zakaria, M. S. Sajab, S. W. Chook, and P. S. Khiew, "CaCO 3decorated cellulose aerogel for removal of Congo Red from aqueous solution," Cellulose, vol. 22, pp. 2683-2691, 2015.

[64] R. Lafi, K. Charradi, M. A. Djebbi, A. B. H. Amara, and A. Hafiane, "Adsorption study of Congo red dye from aqueous solution to $\mathrm{Mg}-\mathrm{Al}$-layered double hydroxide," Advanced Powder Technology, vol. 27, pp. 232-237, 2016.

[65] M. S. Secula, B. Cagnon, I. Cretescu, M. Diaconu, and S. Petrescu, "Removal of an acid dye from aqueous solutions by adsorption on a commercial granular activated carbon: Equilibrium, kinetic and thermodynamic study," Scientific Study \& Research. Chemistry \& Chemical Engineering, Biotechnology, Food Industry, vol. 12, p. 307, 2011.

[66] T. de Carvalho, D. Fungaro, C. Magdalena, and P. Cunico, "Adsorption of indigo carmine from aqueous solution using coal fly ash and zeolite from fly ash," Journal of Radioanalytical and Nuclear Chemistry, vol. 289, pp. 617-626, 2011. 


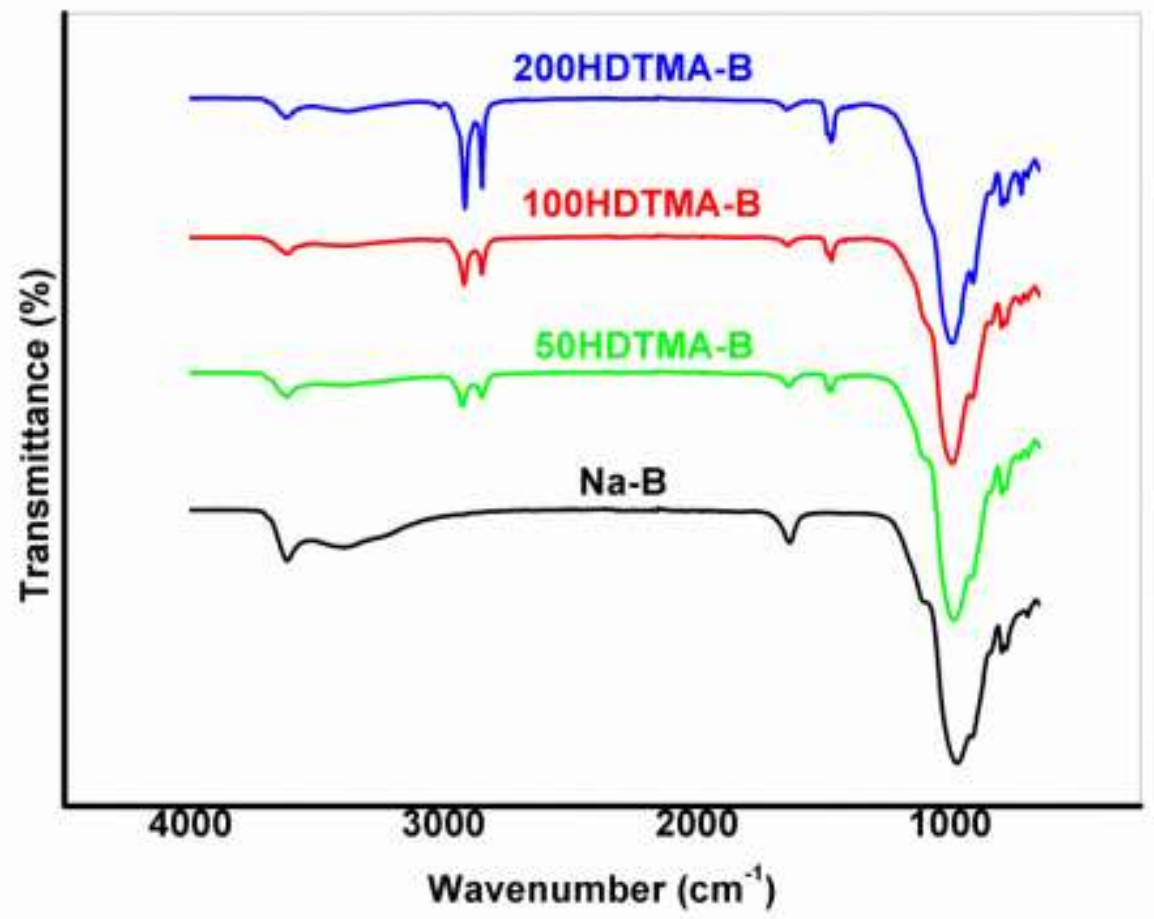

Figure 1. FTIR spectra for sodic Bentonite and hybrid- Bentonites. 

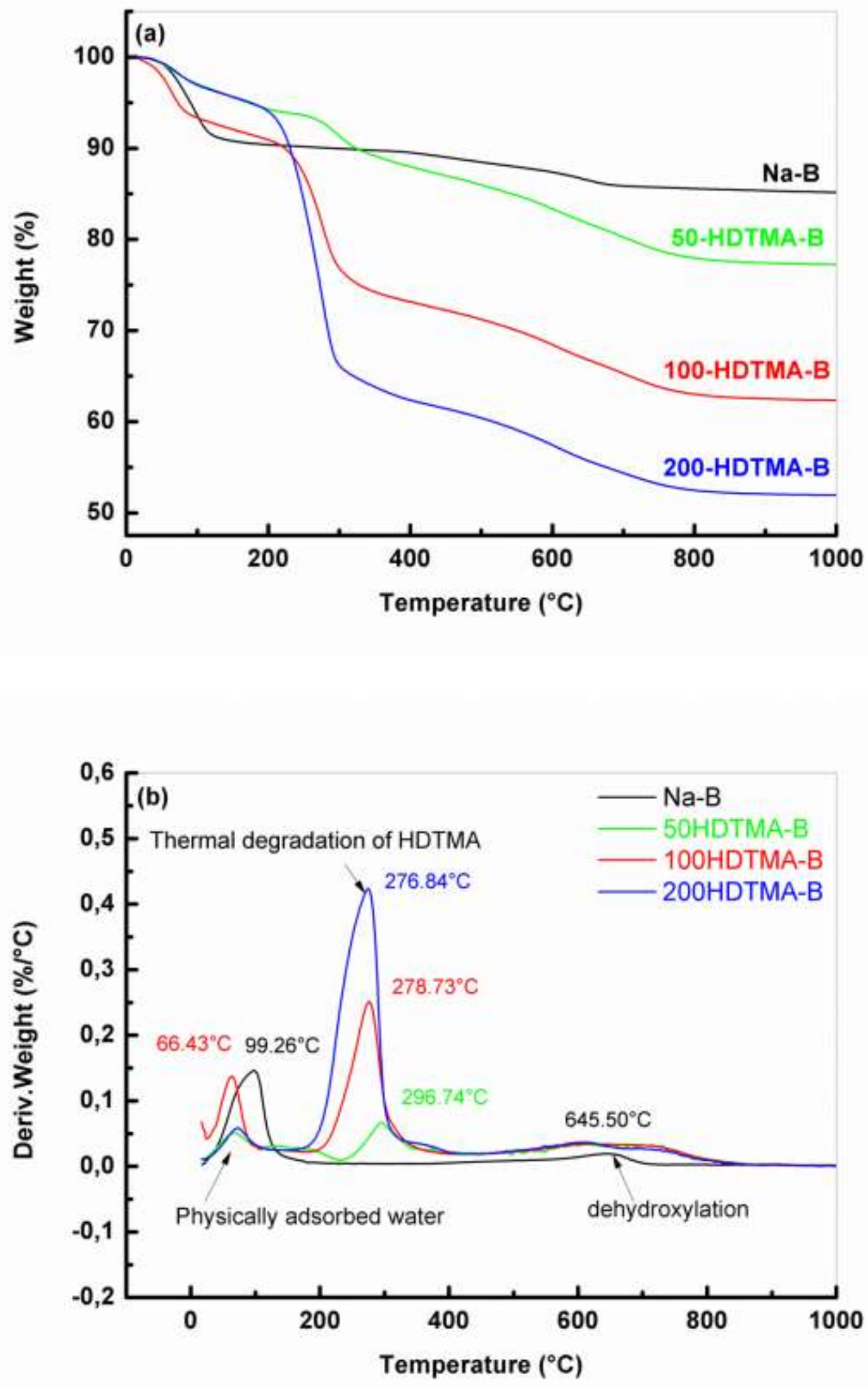

Figure 2. TGA (a) and DTG (b) graphs of Na-B and HDTMA-hybrid-Bentonites 


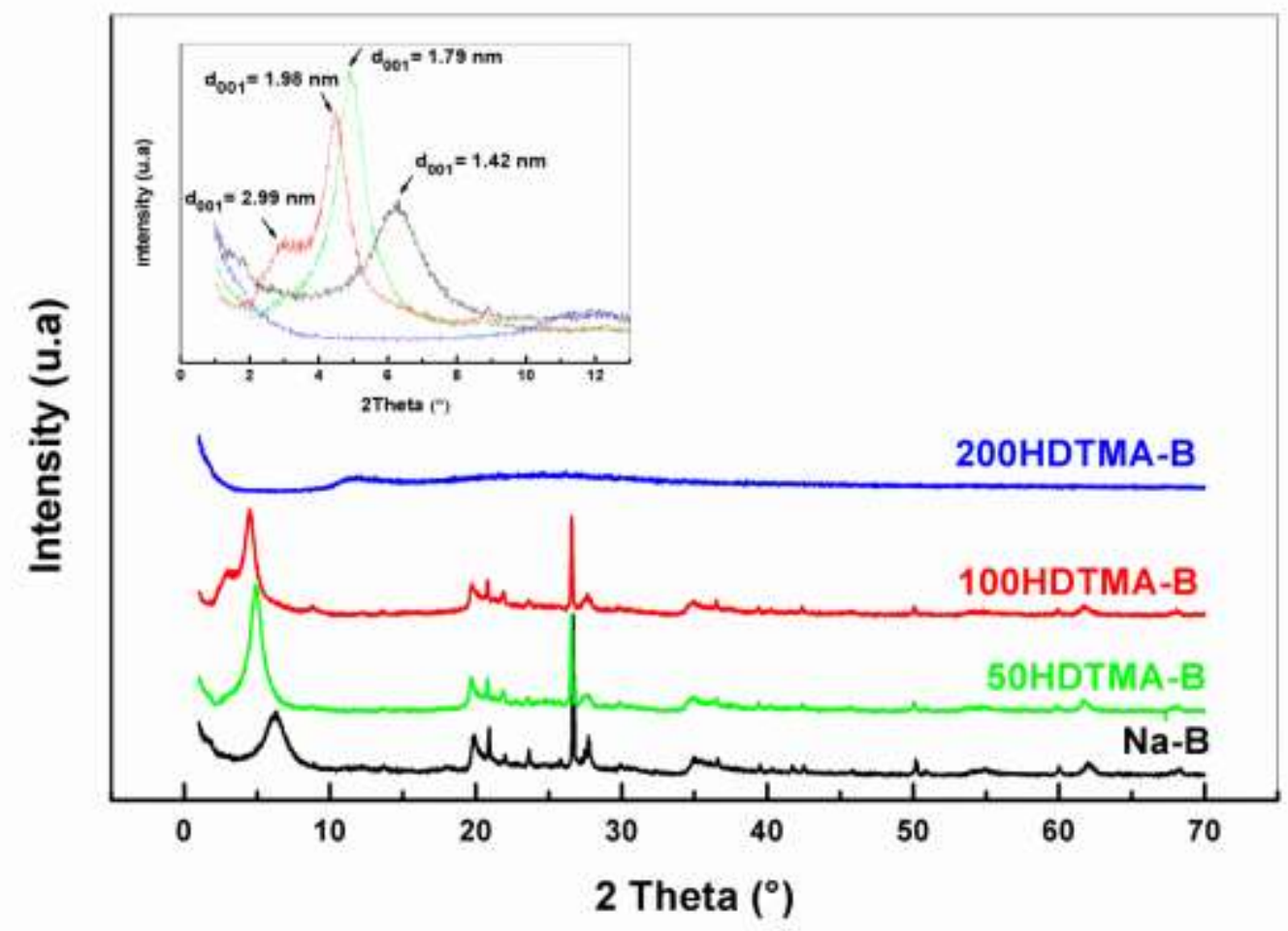

Figure 3. XRD patterns of sodic Bentonite (Na-B) and hybrid- Bentonites. 

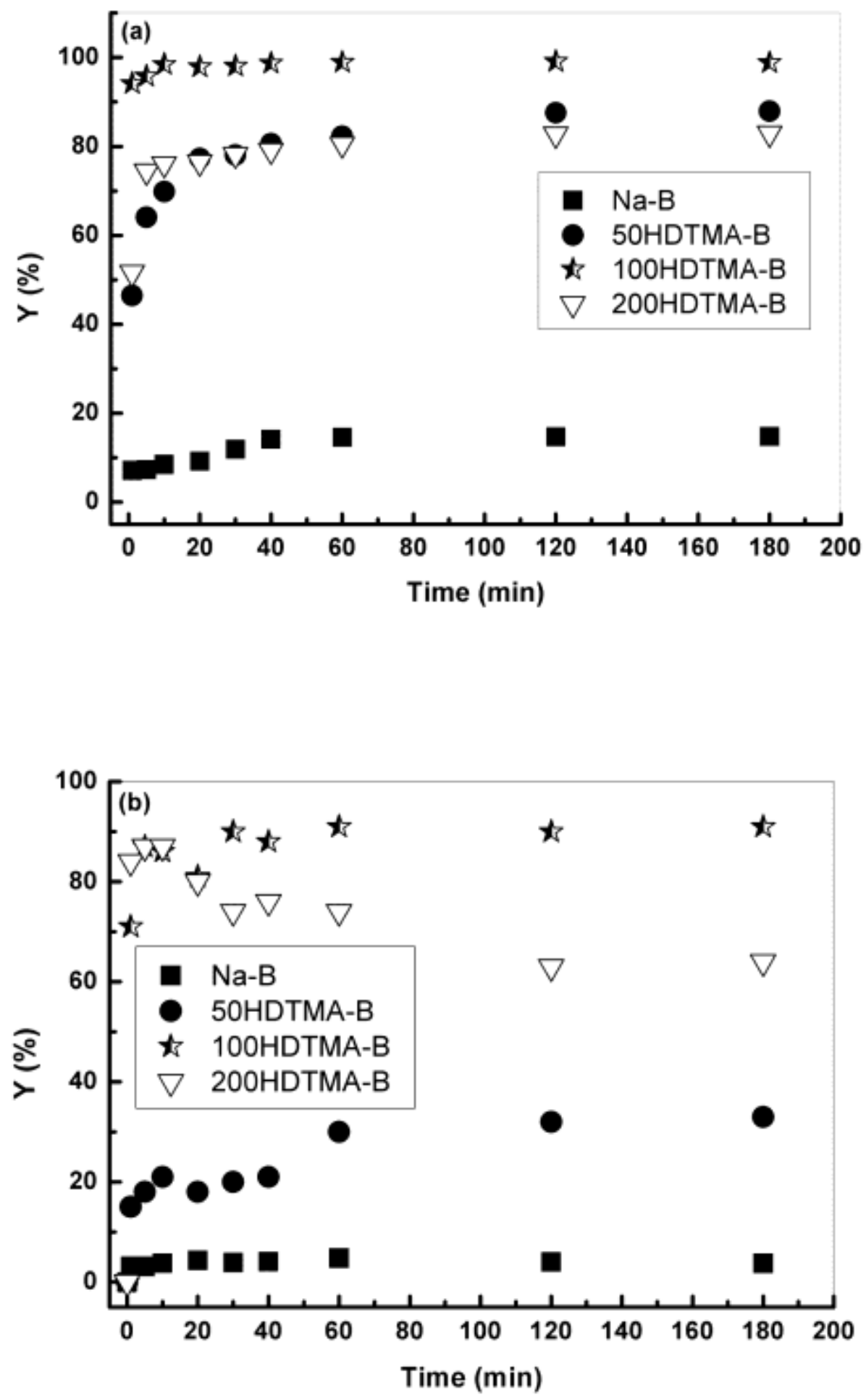

Figure 4. Kinetic curves for $\mathrm{CR}$ (a) and IC (b) adsorption onto hybrid-Bentonite and sodic Bentonite, with $\mathrm{C}_{0}=50 \mathrm{mg} \mathrm{L}^{-1}, \mathrm{~m} / \mathrm{v}=1 \mathrm{~g} \mathrm{~L}^{-1}, \mathrm{pH}=6.6$. 


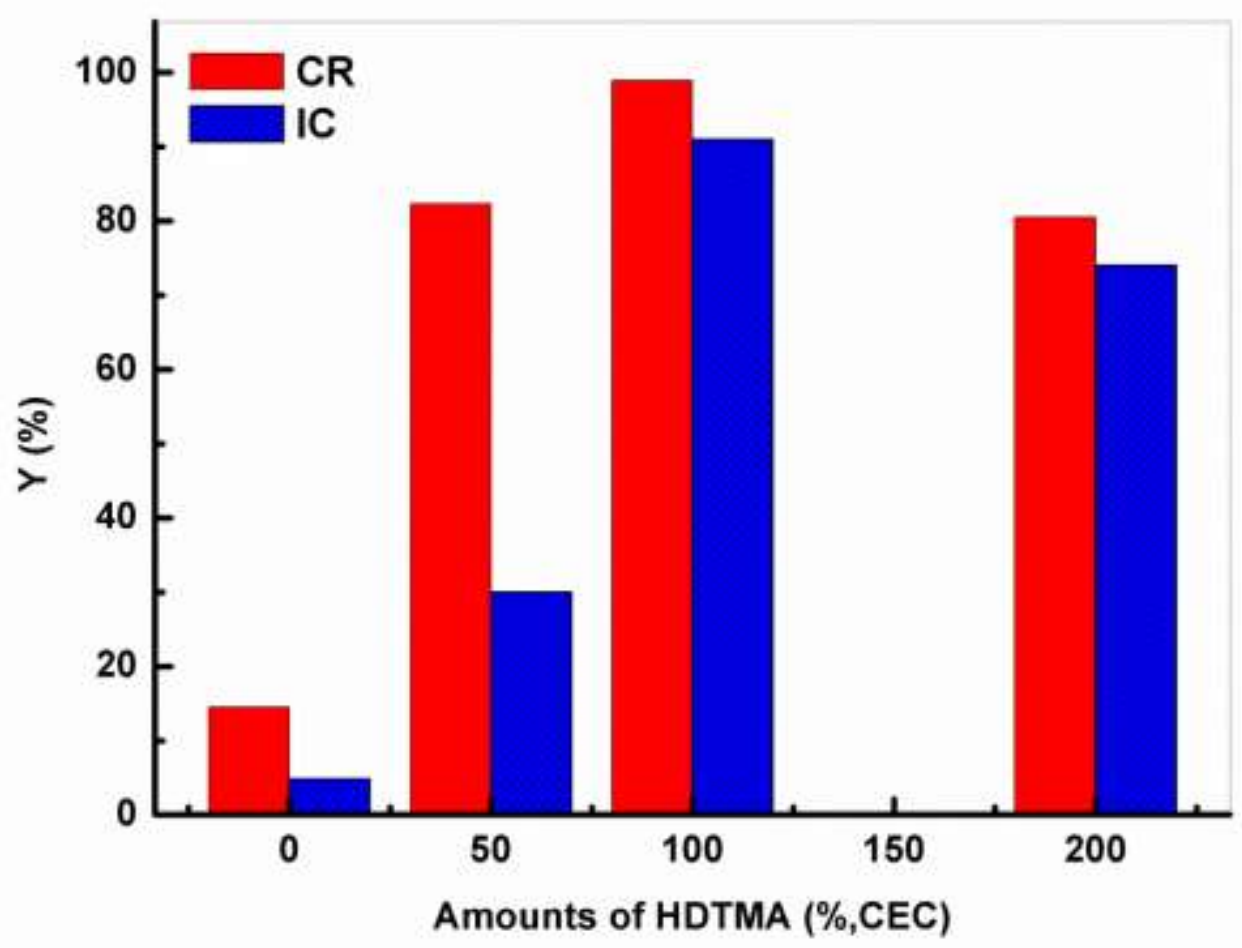

Figure 5. Effect of the amounts of surfactant on the adsorption efficiency of Congo red (CR) and Indigo carmine (IC) on Bentonite samples. 

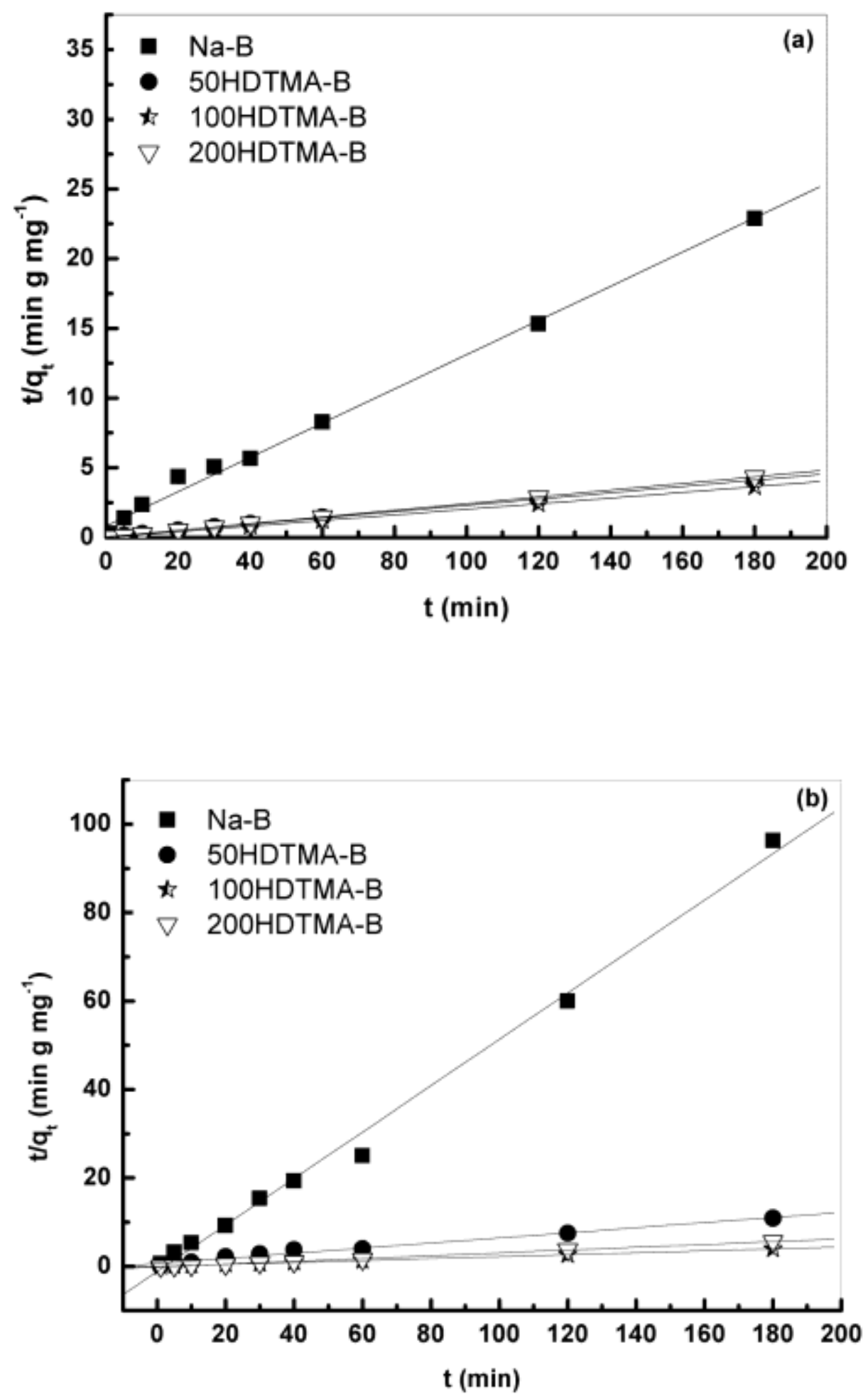

Figure 6. Adsorption kinetics fitted to the pseudo-second-order equation for the retention of $\mathrm{CR}$ (a) and IC (b) on different hybrid-Bentonite samples, with $\mathrm{pH}=6.6, \mathrm{~m} / \mathrm{v}=1 \mathrm{~g} \mathrm{~L}^{-1}, \mathrm{C}_{0}=50$ $\mathrm{mg} \mathrm{L} \mathrm{L}^{-1}$, and $\mathrm{T}=(20 \pm 2){ }^{\circ} \mathrm{C}$. 

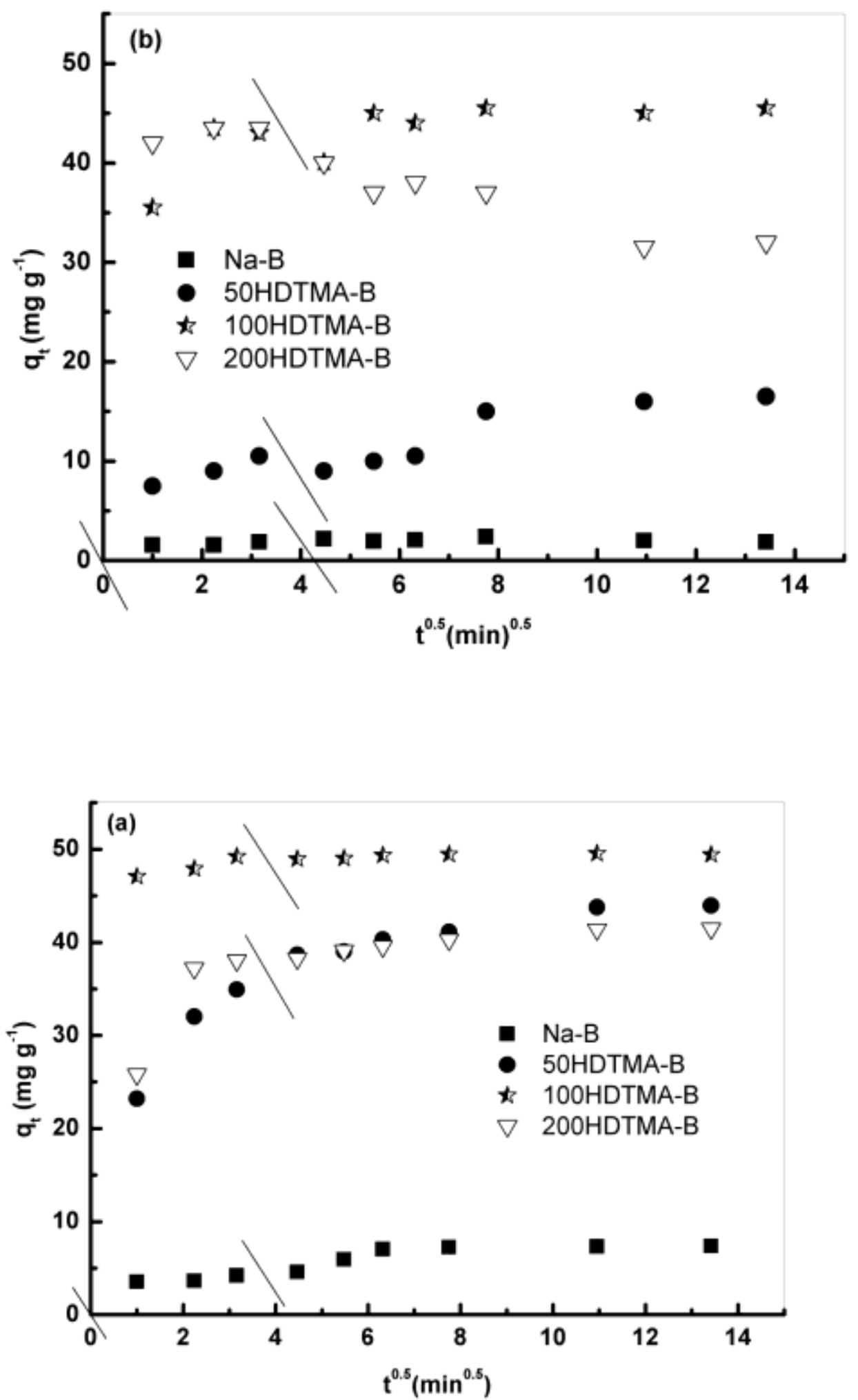

Figure 7. Intraparticle diffusion model for CR (a) and IC (b) adsorption on different Bentonite samples, with $\mathrm{pH}=6.6, \mathrm{~m} / \mathrm{v}=1 \mathrm{~g} \mathrm{~L}^{-1}, \mathrm{C}_{0}=50 \mathrm{mg} \mathrm{L}^{-1}$, and $\mathrm{T}=(20 \pm 2){ }^{\circ} \mathrm{C}$. 

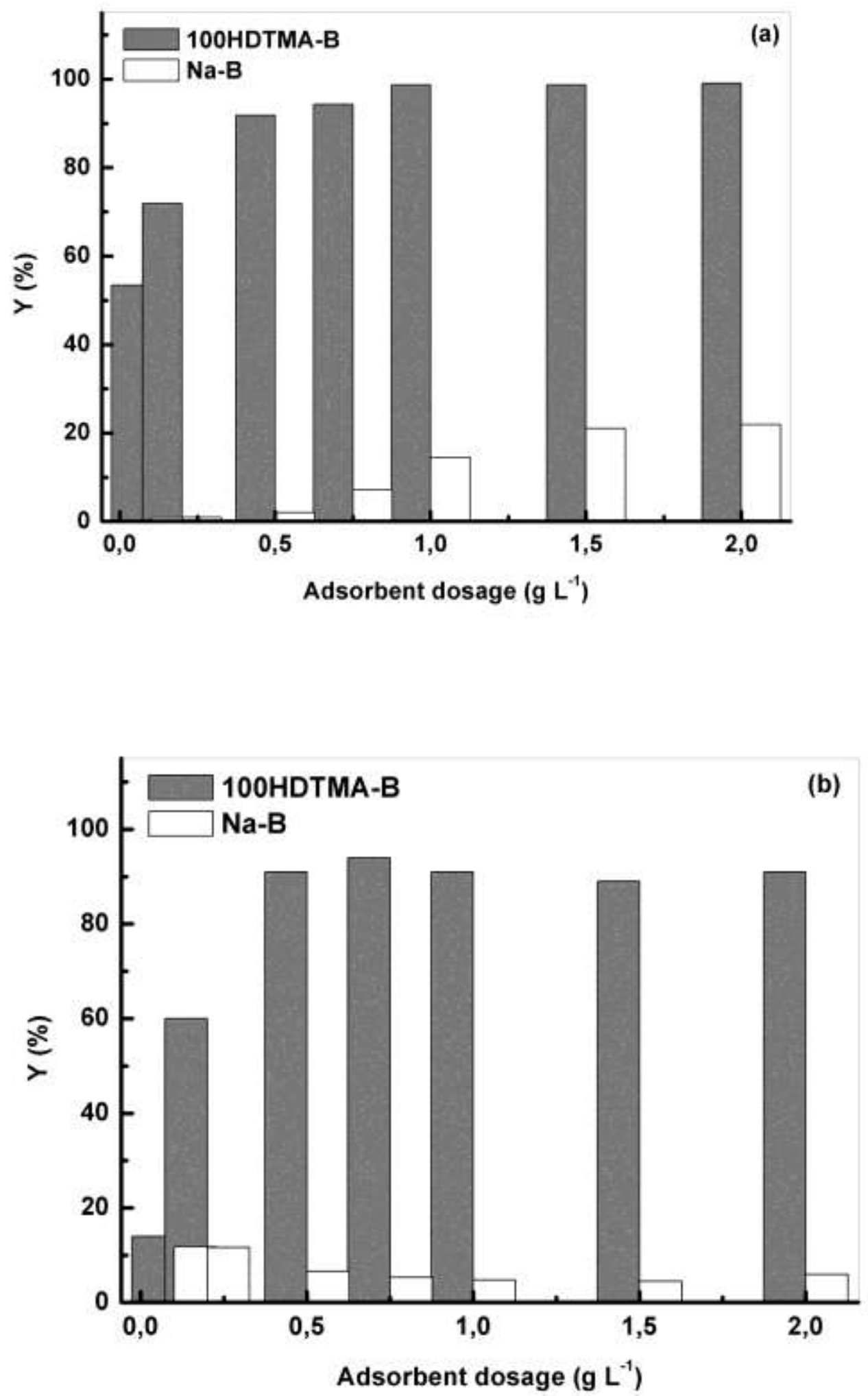

Figure 8. Effect of adsorbent dosage on the removal efficiency of CR (a) and IC (b), with pH $=6.6, \mathrm{C}_{0}=50 \mathrm{mg} \mathrm{L}^{-1}$, and $\mathrm{T}=(20 \pm 2){ }^{\circ} \mathrm{C}$. 

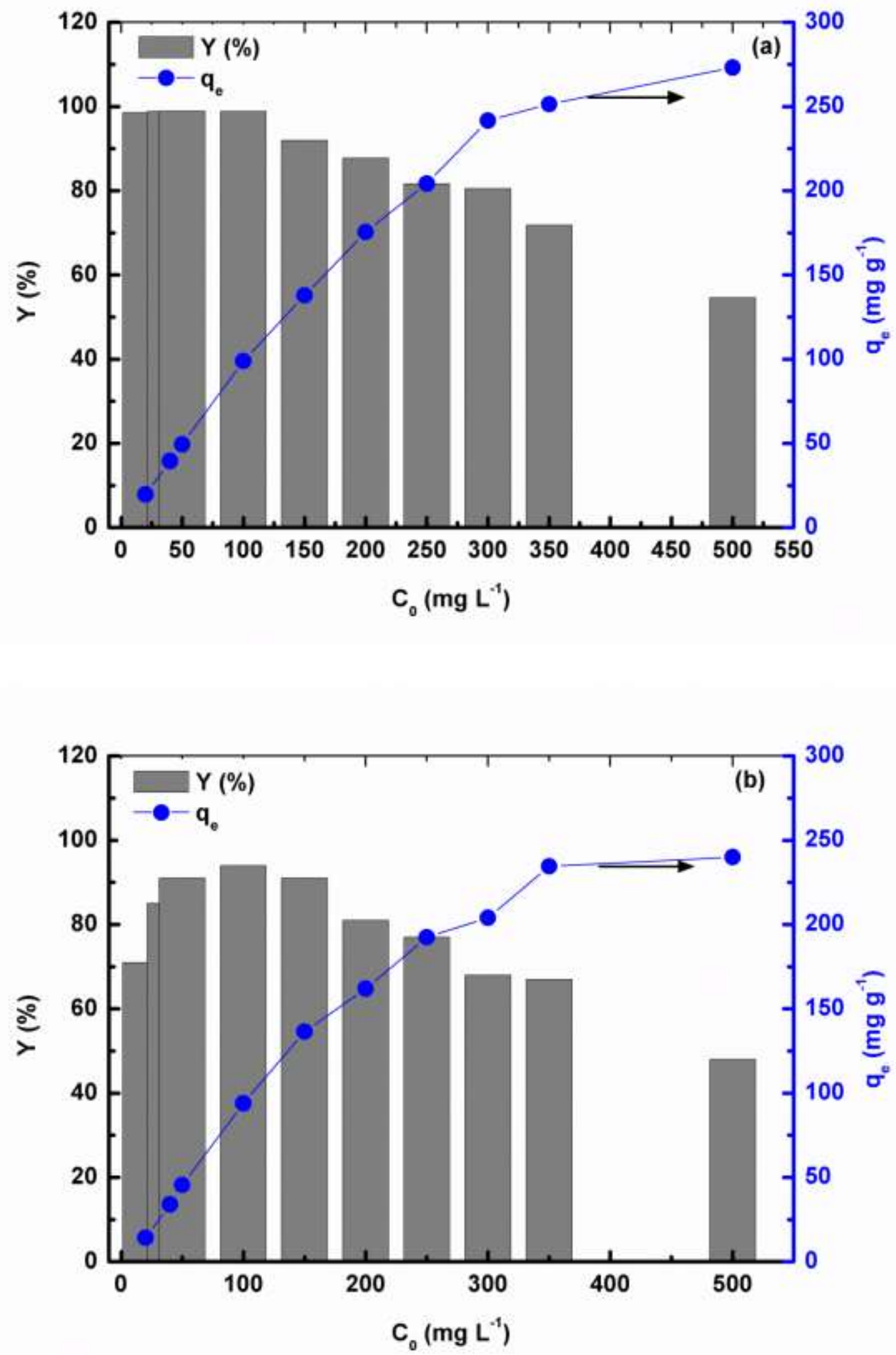

Figure 9. Effect of initial dye concentration on the removal efficiency and adsorption capacity of CR (a) and IC (b) onto 100HDTMA-B, with $\mathrm{pH}=6.6, \mathrm{~m} / \mathrm{v}=1 \mathrm{~g} \mathrm{~L}^{-1}$, and $\mathrm{T}=(20 \pm 2){ }^{\circ} \mathrm{C}$. 


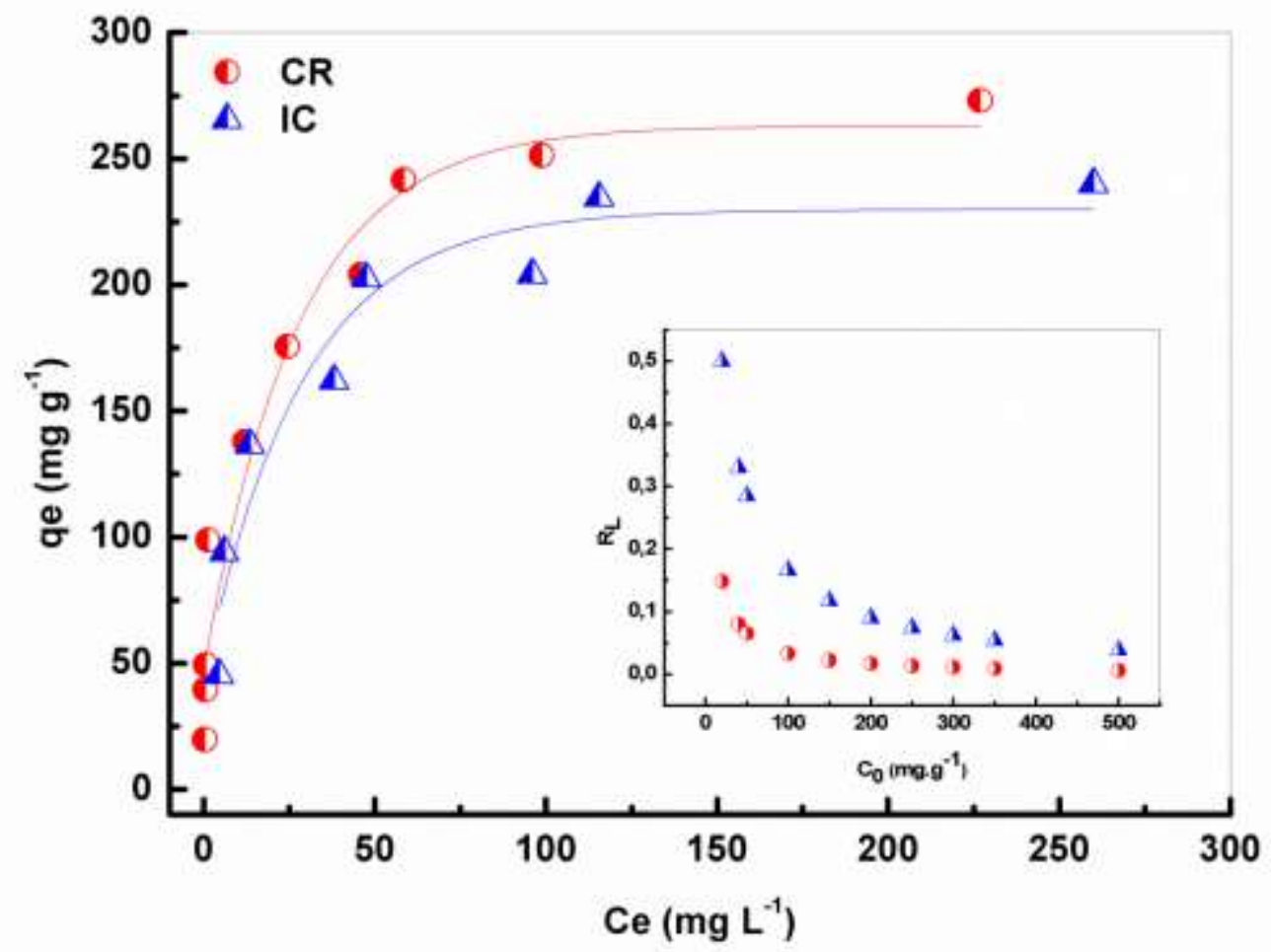

Figure 10. Equilibrium isotherms of $\mathrm{CR}$ and IC adsorption onto hybrid-Bentonite, with $\mathrm{pH}=$ $6.6, \mathrm{~m} / \mathrm{v}=1 \mathrm{~g} \mathrm{~L}^{-1}$, and $\mathrm{T}=(20 \pm 2){ }^{\circ} \mathrm{C}$. 

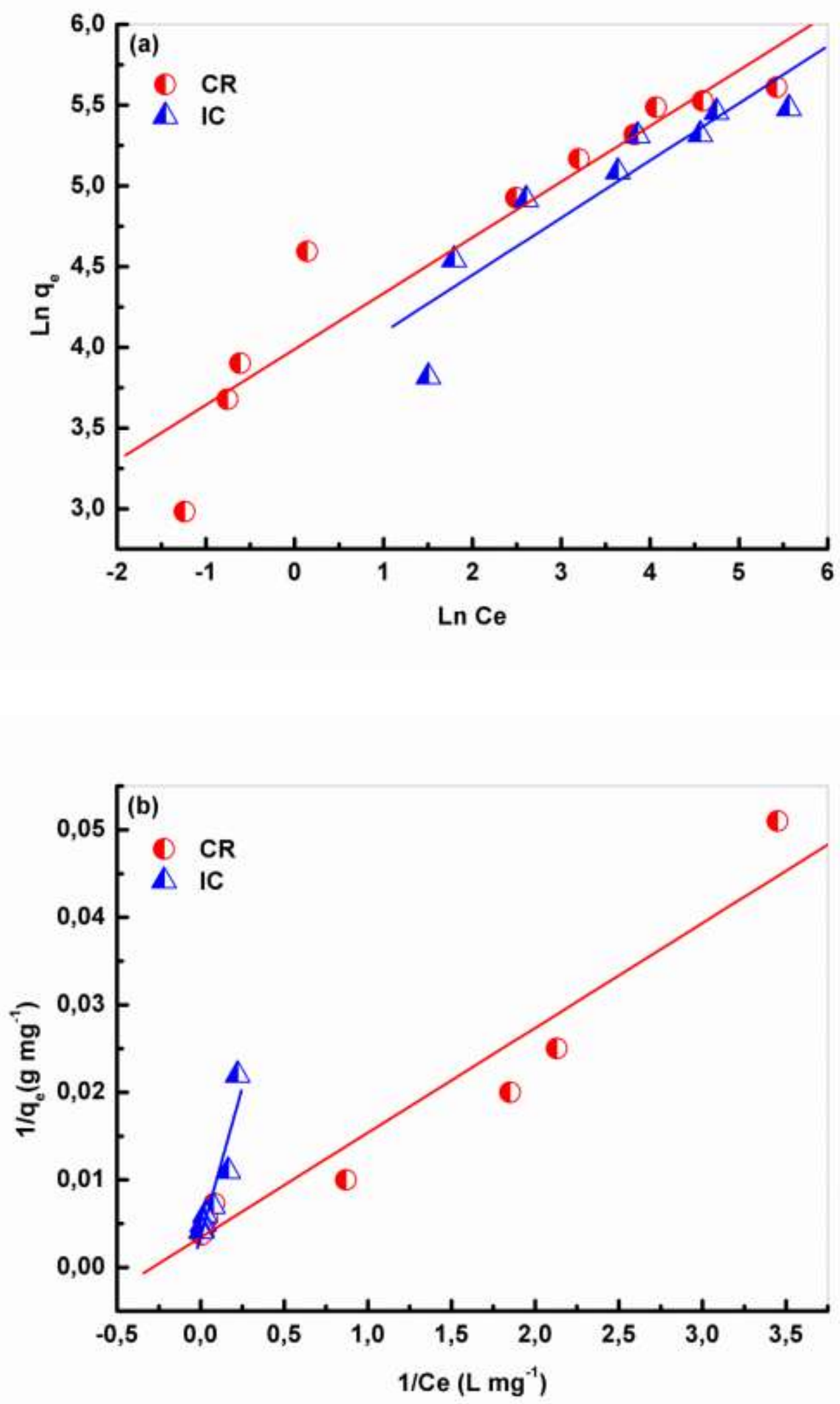

Figure 11. Adsorption isotherms of $\mathrm{CR}$ and IC on hybrid Bentonite fitted by Freundlich (a) and Langmuir (b) equations, with $\mathrm{pH}=6.6, \mathrm{~m} / \mathrm{v}=1 \mathrm{~g} \mathrm{~L}^{-1}$, and $\mathrm{T}=(20 \pm 2){ }^{\circ} \mathrm{C}$. 
Table 1. Chemical compositions (weight \%) of B and Na-B.

\begin{tabular}{lccccccccc}
\hline & $\mathrm{SiO}_{2}$ & $\mathrm{Al}_{2} \mathrm{O}_{3}$ & $\mathrm{Fe}_{2} \mathrm{O}_{3}$ & $\mathrm{MgO}$ & $\mathrm{CaO}$ & $\mathrm{Na}_{2} \mathrm{O}$ & $\mathrm{K}_{2} \mathrm{O}$ & $\mathrm{TiO}_{2}$ & Loss on ignition \\
\hline B & 65.20 & 14.10 & 2.30 & 2.20 & 1.35 & 1.15 & 0.80 & 0.02 & 12.5 \\
& & & & & & & & & \\
$\mathrm{Na}-\mathrm{B}$ & 68.80 & 15.70 & 1.21 & 2.08 & 0.58 & 2.13 & 1.09 & 0.14 & 8.2 \\
\hline
\end{tabular}

Table 2. Structures and properties of selected anionic dyes.

\begin{tabular}{lllll}
\hline $\begin{array}{l}\text { Name } \\
\text { (abbreviation) }\end{array}$ & Chemical structure & $\begin{array}{l}\text { Molecular } \\
\text { formula }\end{array}$ & $\begin{array}{l}\mathbf{M}_{\mathbf{w}} \\
\left(\mathrm{g} \mathrm{mol}^{-1}\right)\end{array}$ & $\begin{array}{l}\lambda \max \\
(\mathbf{n m})\end{array}$ \\
\hline
\end{tabular}

Congo Red

(CR)

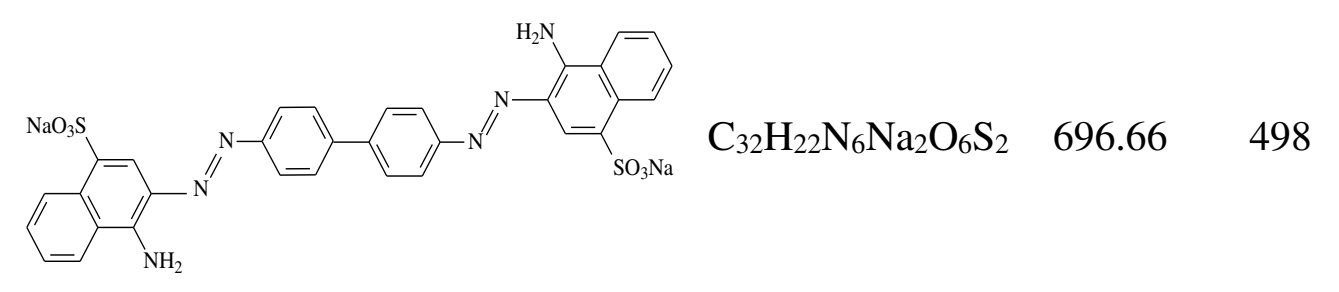

Indigo

Carmine (IC)

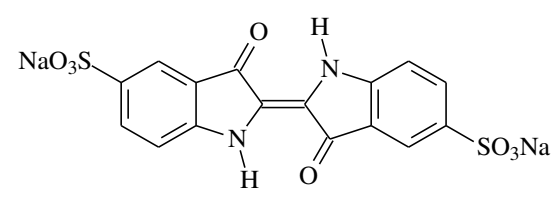

$\mathrm{C}_{16} \mathrm{H}_{8} \mathrm{~N}_{2} \mathrm{Na}_{2} \mathrm{O}_{8} \mathrm{~S}_{2} \quad 466.36 \quad 610$ 
Table 3. Kinetic parameters for Congo red and indigo carmine sorption

\begin{tabular}{|c|c|c|c|c|c|c|c|c|c|c|c|}
\hline \multirow[t]{2}{*}{ Sorbate } & \multirow[t]{2}{*}{ Sorbent } & \multirow[b]{2}{*}{$q_{e, e x p}$} & \multicolumn{3}{|c|}{ Pseudo-first-order } & \multicolumn{3}{|c|}{ Pseudo-second-order } & \multicolumn{3}{|c|}{ Intra-particle diffusion } \\
\hline & & & $q_{e, c a l}$ & $k_{1}$ & $\mathbf{R}^{2}$ & $k_{2}$ & $q_{e, c a l}$ & $\mathbf{R}^{2}$ & $\mathbf{k}_{\mathbf{i d}}$ & $\mathbf{I}$ & $\mathbf{R}^{2}$ \\
\hline & Na-B & 7.25 & 6.06 & 0.068 & 0.84 & 0.50 & 8.13 & 0.99 & 1.18 & 0.97 & 0.85 \\
\hline \multirow{4}{*}{$\begin{array}{l}\text { Congo } \\
\text { red }\end{array}$} & 50НDТМА-В & 43.14 & 18.32 & 0.039 & 0.77 & 0.01 & 45.45 & 0.99 & 10.6 & 5.60 & 0.93 \\
\hline & 100HDTMA-B & 49.36 & 4.53 & 0.092 & 0.63 & 0.19 & 50.00 & 0.99 & 13.74 & 14.06 & 0.79 \\
\hline & 200HDTMA-B & 40.28 & 11.04 & 0.045 & 0.66 & 0.03 & 41.66 & 0.99 & 11.75 & 6.47 & 0.91 \\
\hline & Na-B & 2.40 & 0.95 & 0.008 & 0.37 & -0.62 & 1.90 & 0.99 & 0.52 & 0.42 & 0.85 \\
\hline \multirow{3}{*}{$\begin{array}{l}\text { Indigo } \\
\text { carmine }\end{array}$} & 50НDTMA-B & 15 & 2.57 & 0.013 & 0.82 & 0.005 & 17.33 & 0.99 & 3.06 & 1.85 & 0.91 \\
\hline & 100HDTMA-B & 45.5 & 1.77 & 0.002 & 0.04 & 0.03 & 45.66 & 0.99 & 12.77 & 10.06 & 0.86 \\
\hline & 200HDTMA-B & 37 & 1.19 & 0.015 & 0.44 & -0.01 & 31.45 & 0.99 & 12.23 & 12.67 & 0.79 \\
\hline
\end{tabular}

$\mathrm{q}_{\mathrm{e}, \exp }\left(\mathrm{mg} \mathrm{g}^{-1}\right), \mathrm{q}_{\mathrm{e}, \mathrm{cal}}\left(\mathrm{mg} \mathrm{g}^{-1}\right), \mathrm{k}_{1}\left(\mathrm{~min}^{-1}\right), \mathrm{k}_{2}\left(\mathrm{~g} \mathrm{mg}^{-1} \min ^{-1}\right), \mathrm{k}_{\mathrm{id}}\left(\mathrm{mg} \mathrm{g}^{-1} \min ^{-0.5}\right)$, and I $\left(\mathrm{mg} \mathrm{g}^{-1}\right)$ 
Table 4. Comparison of the amounts of $\mathrm{CR}$ and IC dyes removed at equilibrium $\left(\mathrm{q}_{\mathrm{e}}\right)$ by HDTMA-modified Bentonite in this study with those reported in previous studies where different adsorbents were applied (kinetic studies).

\begin{tabular}{|c|c|c|c|c|c|c|c|c|}
\hline Adsorbents & Adsorbates & $\mathbf{m} / \mathbf{v}$ & pH & $\mathbf{C}_{0}$ & $\mathbf{T}$ & $\mathbf{t e}_{\mathbf{e}}$ & $\mathbf{q e}$ & Ref. \\
\hline \multicolumn{9}{|l|}{ Unmodified clay } \\
\hline Montmorillonite & IC & 0.5 & $3-7$ & 50 & 22 & - & 19.67 & [57] \\
\hline Na-Bentonite & $\mathrm{CR}$ & 100 & 7.5 & 150 & 30 & - & 7.51 & {$[58]$} \\
\hline Kaolin & $\mathrm{CR}$ & 100 & 7.5 & 150 & 30 & - & 6.27 & {$[58]$} \\
\hline \multicolumn{9}{|l|}{ Modified clay } \\
\hline Polydiallydimethylammonium & IC & 1 & 5 & 46.6 & 25 & 80 & 52.51 & {$[16]$} \\
\hline \multicolumn{9}{|l|}{ modified Bentonite } \\
\hline Hexadecyltrimethylammonium & $\mathrm{CR}$ & 2 & - & 250 & 30 & 120 & 116 & [59] \\
\hline \multicolumn{9}{|l|}{ modified attapulgite clay } \\
\hline Carbonized leonardite & $\mathrm{CR}$ & 1.25 & $5-9$ & 100 & 25 & 240 & 73.53 & {$[60]$} \\
\hline Hexadecyltrimethylammonium & $\mathrm{CR}$ & 1 & 6.6 & 50 & 20 & 60 & 49.36 & This \\
\hline modified & IC & 1 & 6.6 & 50 & 20 & 60 & 45.5 & study \\
\hline \multicolumn{9}{|l|}{ (100HDTMA-B) } \\
\hline Other adsorbents & $\mathrm{CR}$ & & & & & & & \\
\hline Surfactant modified pumice & $\mathrm{CR}$ & 5 & $5-11$ & 50 & 25 & 1440 & 7.64 & {$[61]$} \\
\hline Metal hydroxides sludge (MHS) & $\mathrm{CR}$ & 2.5 & 6 & 50 & 20 & 30 & 19.6 & [62] \\
\hline gum-graft-poly & $\mathrm{CR}$ & 1.6 & 3 & 150 & 45 & 30 & 233.4 & {$[56]$} \\
\hline \multicolumn{9}{|l|}{$($ acrylamide $) /$ silica $\quad\left(\mathrm{g}-\mathrm{GG} / \mathrm{SiO}_{2}\right)$} \\
\hline \multicolumn{9}{|l|}{ nanocomposite } \\
\hline Polyaniline / Bismuth tungstate & $\mathrm{CR}$ & 0.5 & 6 & 50 & 20 & 90 & 86.76 & {$[46]$} \\
\hline \multicolumn{9}{|l|}{$\left(\mathrm{PANi} / \mathrm{Bi}_{2} \mathrm{WO}_{6}\right)$ nanocomposites } \\
\hline CaCO3-loaded cellulose aerogel & $\mathrm{CR}$ & 2 & - & 50 & 20 & - & 25.47 & {$[63]$} \\
\hline
\end{tabular}




\begin{tabular}{|c|c|c|c|c|c|c|c|c|}
\hline Mg-Al-layered & $\mathrm{CR}$ & 2 & 4 & 80 & 25 & 20 & 32.25 & [64] \\
\hline \multicolumn{9}{|l|}{ hydroxide (Mg-Al-LDH) } \\
\hline Commercial granular activated & IC & 1 & 5.5 & 50 & 25 & - & 47.17 & [65] \\
\hline \multicolumn{9}{|l|}{ carbon } \\
\hline Coal fly ash (FA) & IC & 10 & - & 14.7 & 25 & 45.5 & 1.24 & [66] \\
\hline Zeolitic material (ZM) & IC & 10 & - & 11 & 25 & 240 & 0.99 & [66] \\
\hline
\end{tabular}
$\mathrm{m} / \mathrm{v}\left(\mathrm{g} \mathrm{L}^{-1}\right), \mathrm{C}_{0}\left(\mathrm{mg} \mathrm{L}^{-1}\right), \mathrm{T}\left({ }^{\circ} \mathrm{C}\right), \mathrm{t}_{\mathrm{e}}(\mathrm{min}), \mathrm{q}_{\mathrm{e}}\left(\mathrm{mg} \mathrm{g}^{-1}\right)$ 
Table 5. Adsorption isotherm constants for the adsorption of CR and IC on HDTMA-modified Bentonite

\begin{tabular}{|c|c|c|c|c|c|c|}
\hline \multirow[t]{2}{*}{ Sorbate } & \multicolumn{3}{|c|}{ Freundlich } & \multicolumn{3}{|l|}{ Langmuir } \\
\hline & $n$ & $K_{F}\left(\mathrm{~L} \mathrm{~g}^{-1}\right)$ & $\overline{R^{2}}$ & $q_{m}\left(\mathrm{mg} \mathrm{g}^{-1}\right)$ & $b\left(\mathrm{~L} \mathrm{~g}^{-1}\right)$ & $R^{2}$ \\
\hline Congo red & 2.90 & 54.00 & 0.94 & 292.4 & 0.286 & 0.97 \\
\hline Indigo carmine & 2.82 & 42.03 & 0.90 & 289.0 & 0.050 & 0.94 \\
\hline
\end{tabular}


Figures

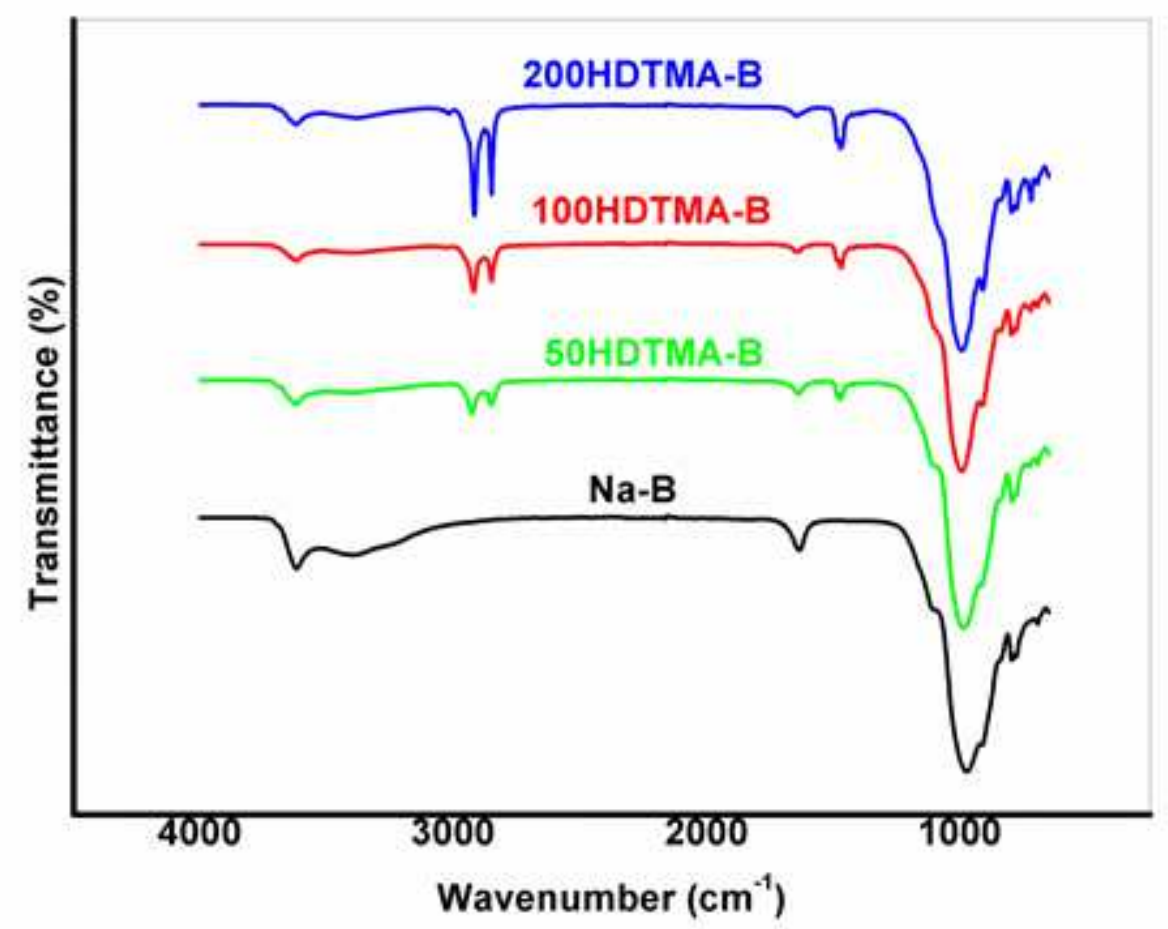

Figure 1

FTIR spectra for sodic Bentonite and hybrid- Bentonites. 

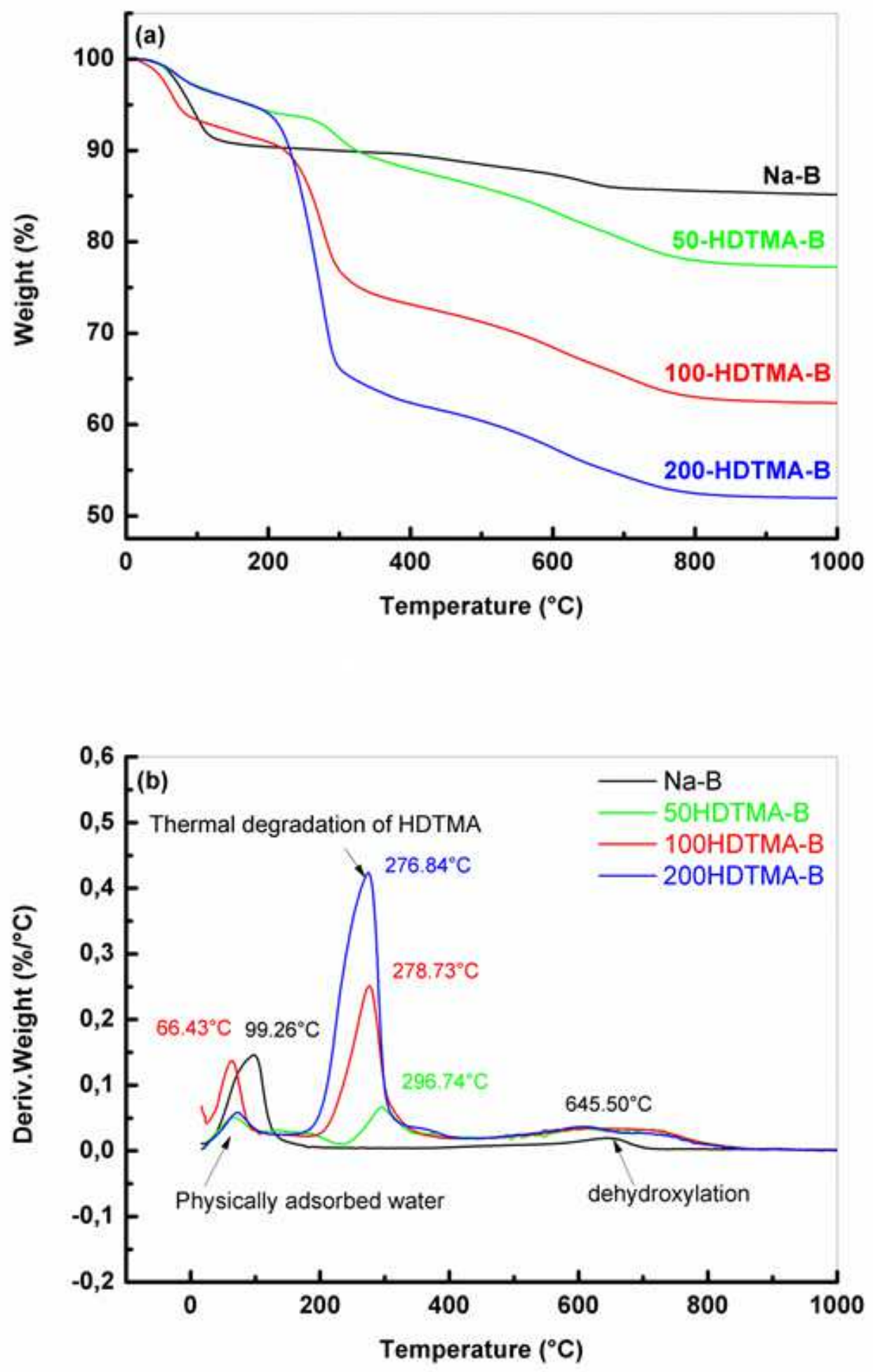

Figure 2

TGA (a) and DTG (b) graphs of Na-B and HDTMA-hybrid-Bentonites 


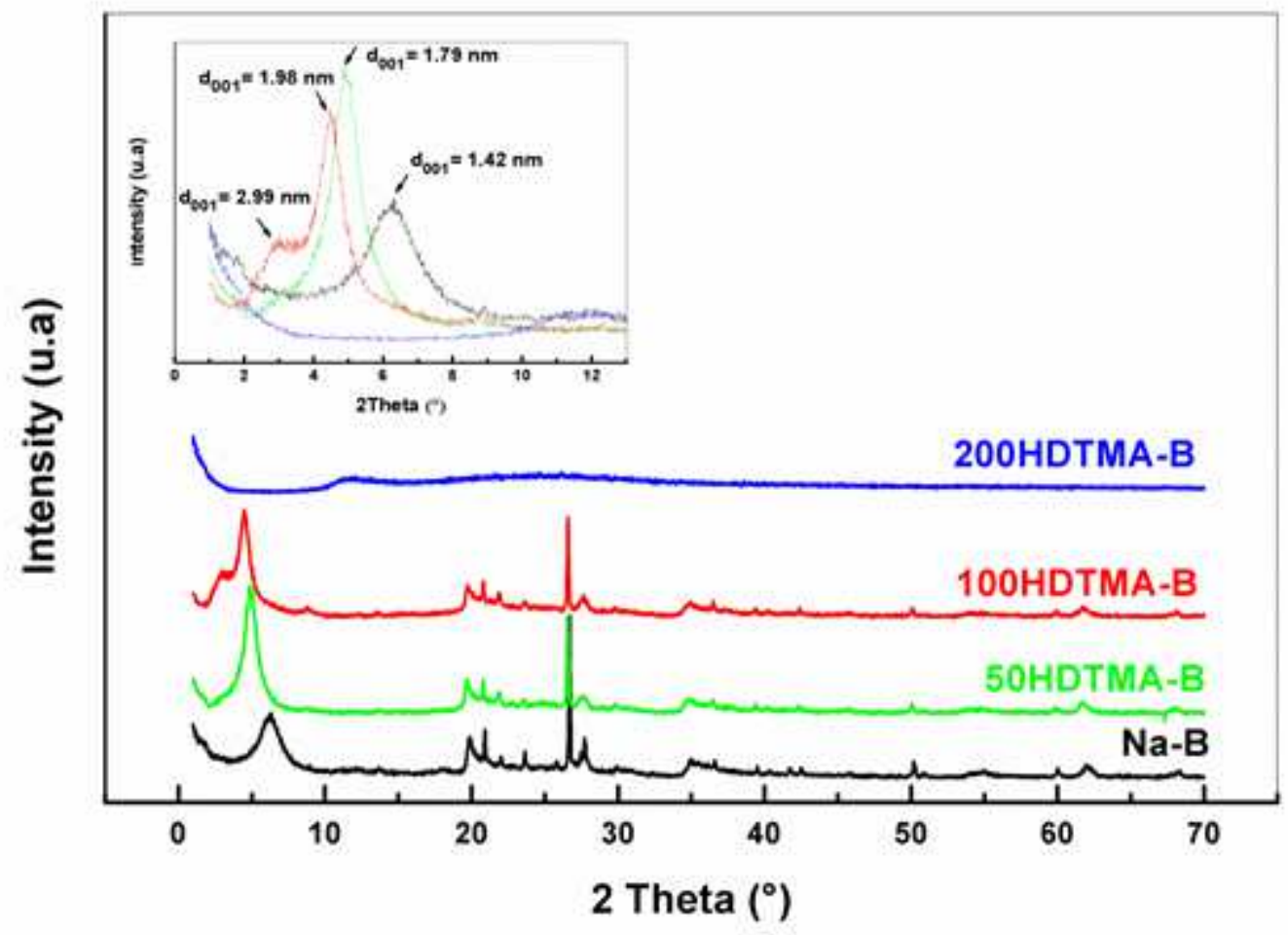

Figure 3

XRD patterns of sodic Bentonite (Na-B) and hybrid- Bentonites. 

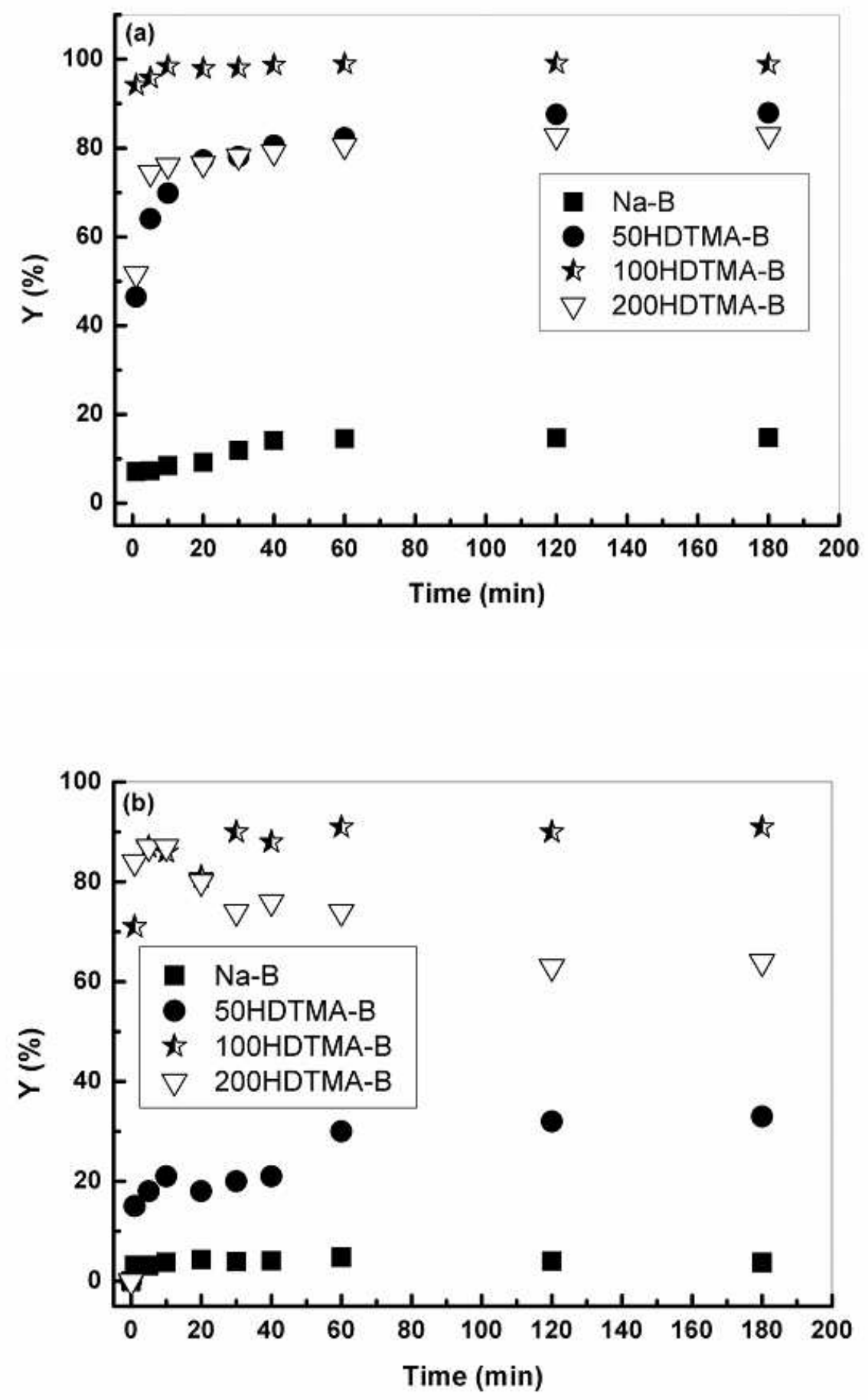

Figure 4

Kinetic curves for CR (a) and IC (b) adsorption onto hybrid-Bentonite and sodic Bentonite, with $\mathrm{CO}=50$ $\mathrm{mg} \mathrm{L}-1, \mathrm{~m} / \mathrm{v}=1 \mathrm{~g} \mathrm{~L}-1, \mathrm{pH}=6.6$. 


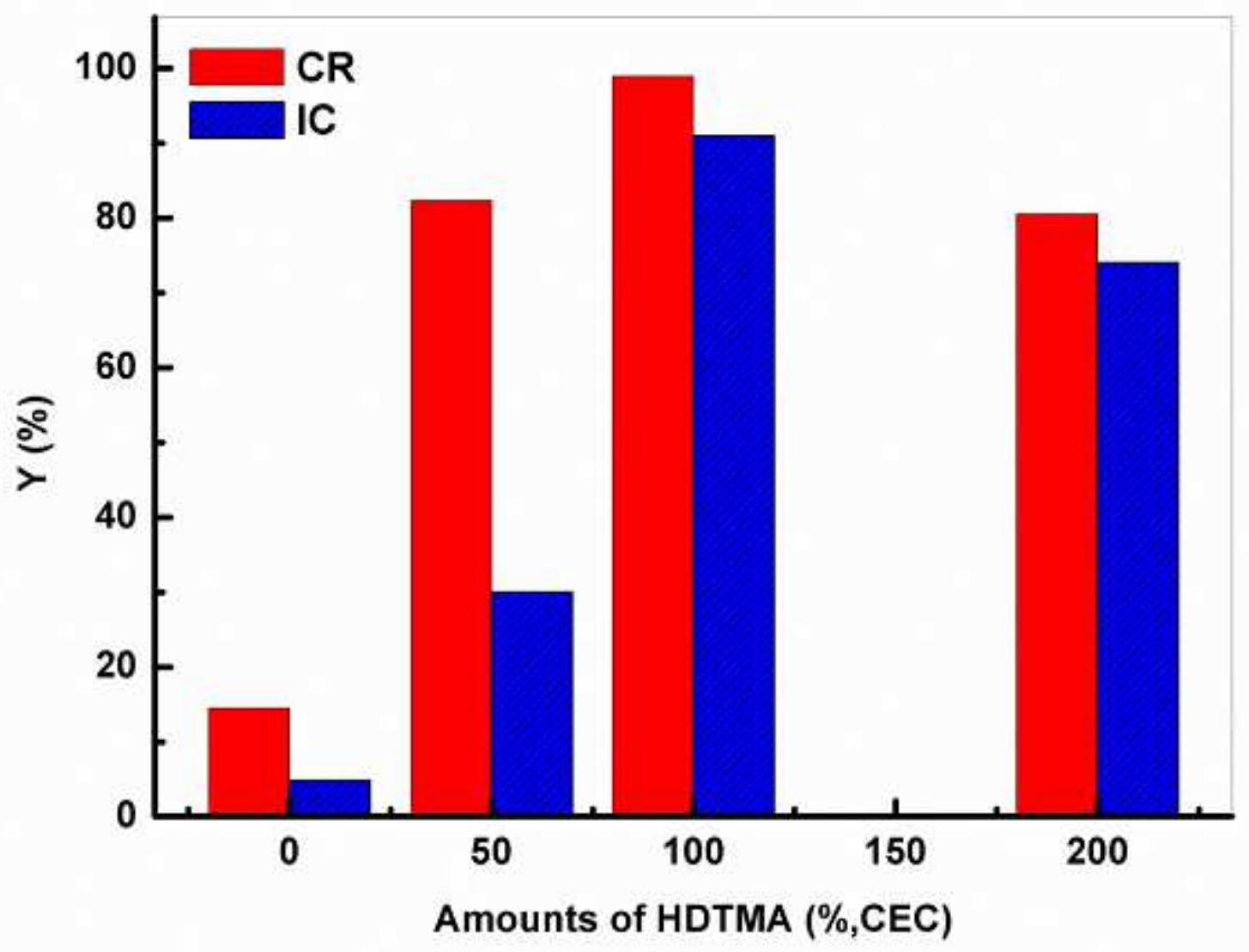

Figure 5

Effect of the amounts of surfactant on the adsorption efficiency of Congo red (CR) and Indigo carmine (IC) on Bentonite samples. 

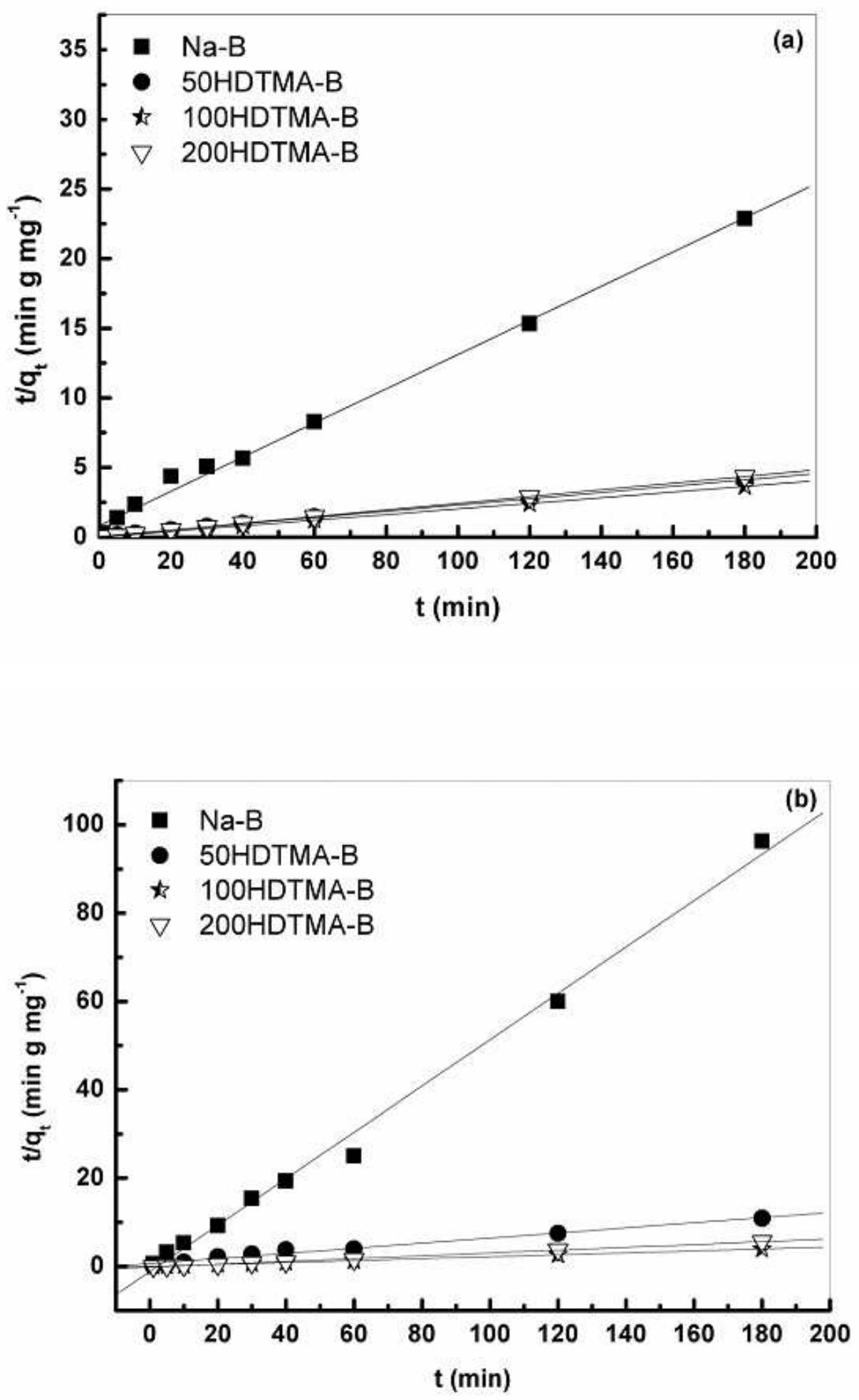

Figure 6

Adsorption kinetics fitted to the pseudo-second-order equation for the retention of CR (a) and IC (b) on different hybrid-Bentonite samples, with $\mathrm{pH}=6.6, \mathrm{~m} / \mathrm{v}=1 \mathrm{~g} \mathrm{~L}-1, \mathrm{C} 0=50 \mathrm{mg} \mathrm{L}-1$, and $\mathrm{T}=(20 \pm 2){ }^{\circ} \mathrm{C}$. 

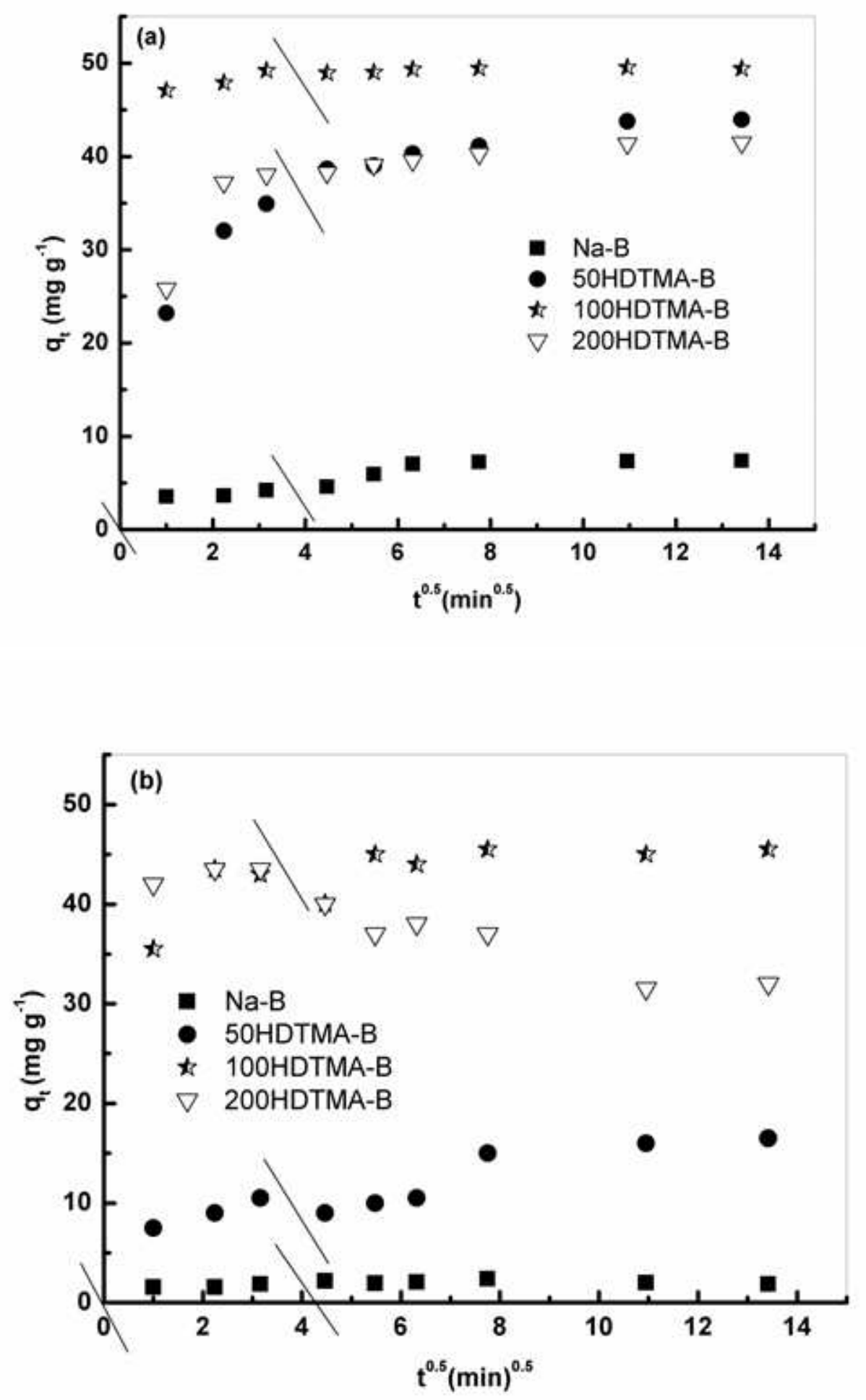

Figure 7

Intraparticle diffusion model for CR (a) and IC (b) adsorption on different Bentonite samples, with $\mathrm{pH}=$ $6.6, \mathrm{~m} / \mathrm{v}=1 \mathrm{~g} \mathrm{~L}-1, \mathrm{C} 0=50 \mathrm{mg} \mathrm{L}-1$, and $\mathrm{T}=(20 \pm 2){ }^{\circ} \mathrm{C}$. 

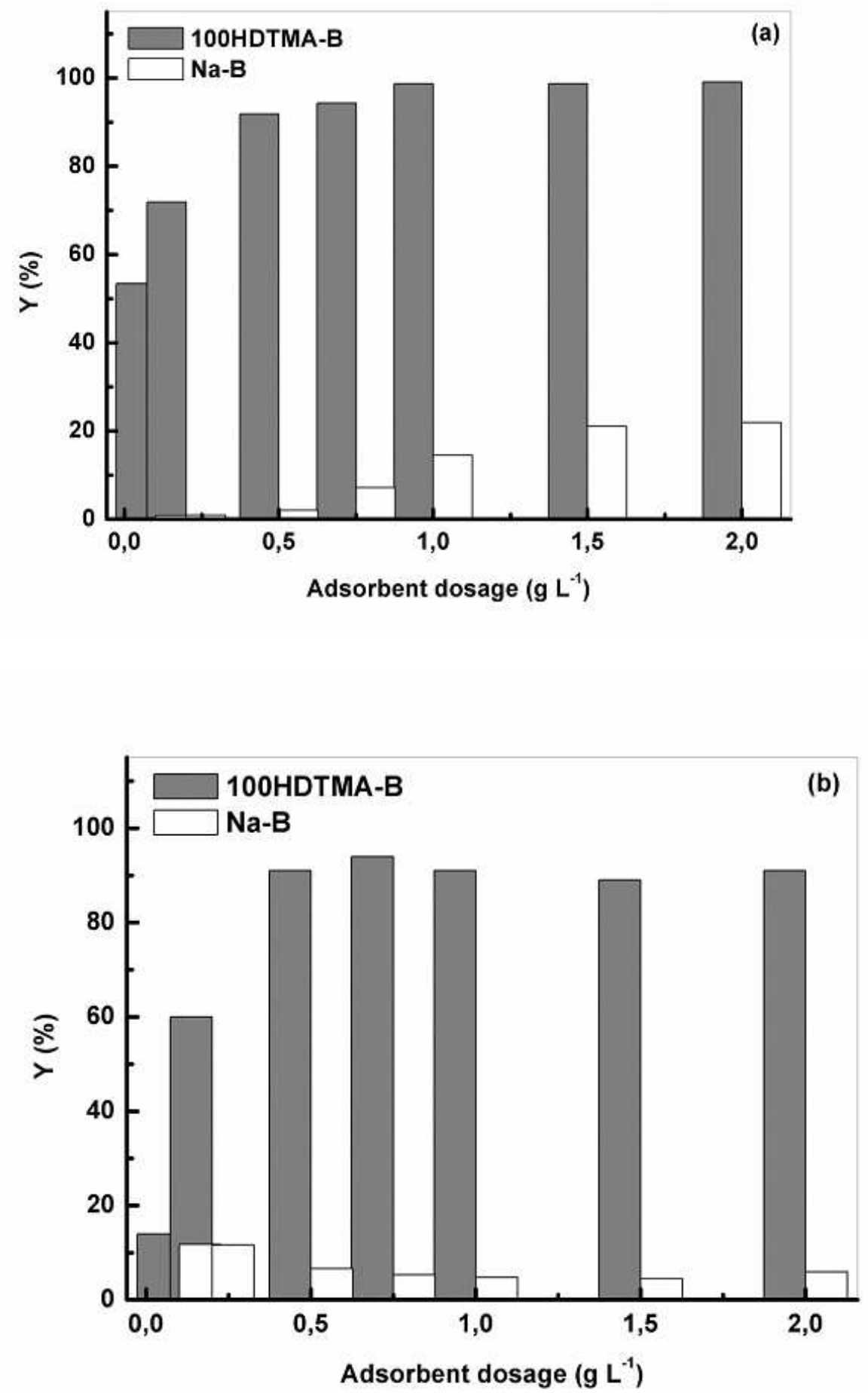

Figure 8

Effect of adsorbent dosage on the removal efficiency of CR (a) and IC (b), with $\mathrm{pH}=6.6, \mathrm{CO}=50 \mathrm{mg} \mathrm{L}-1$, and $\mathrm{T}=(20 \pm 2)^{\circ} \mathrm{C}$. 

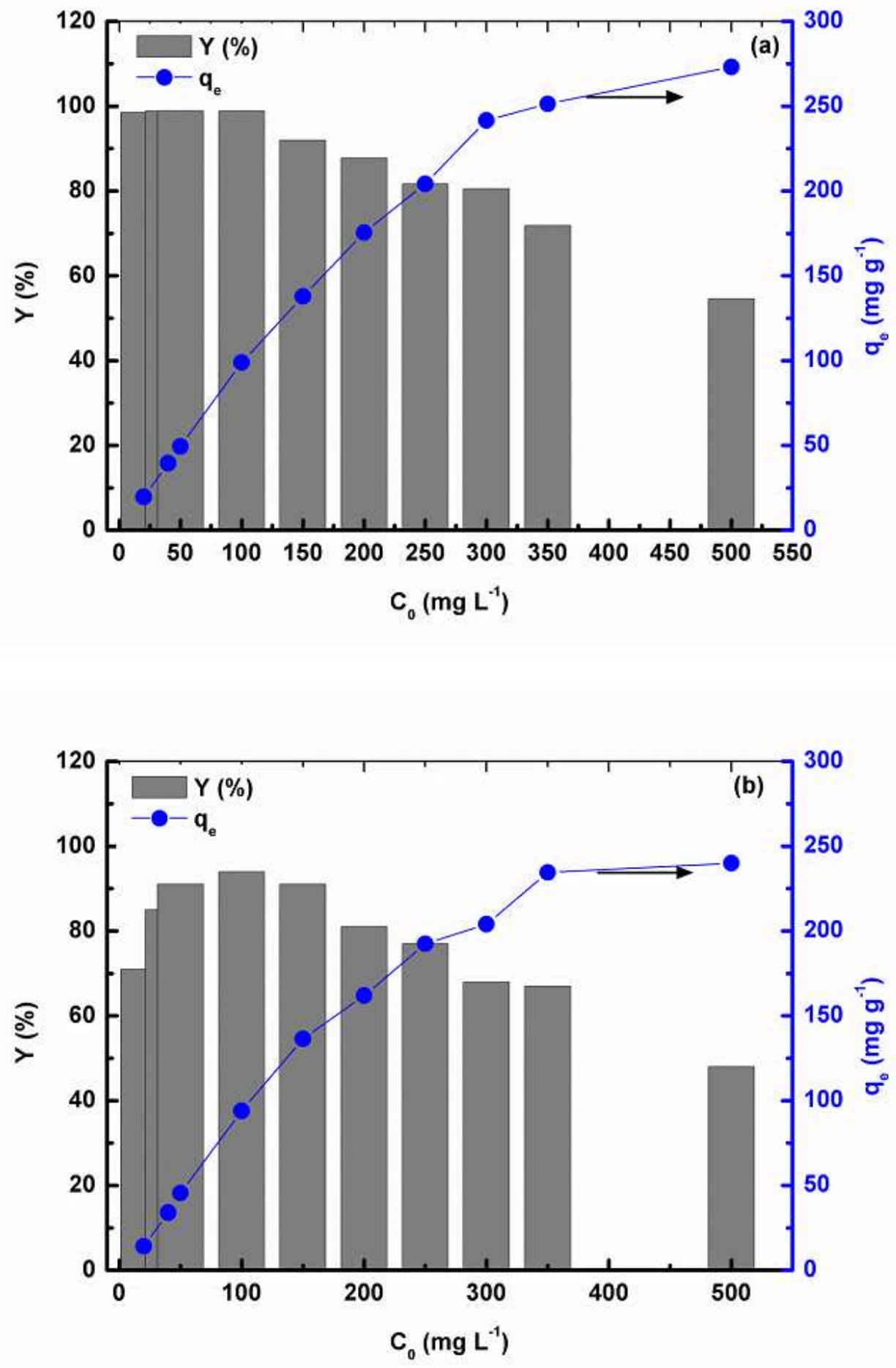

Figure 9

Effect of initial dye concentration on the removal efficiency and adsorption capacity of CR (a) and IC (b) onto 100HDTMA-B, with $\mathrm{pH}=6.6, \mathrm{~m} / \mathrm{v}=1 \mathrm{~g} \mathrm{~L}-1$, and $\mathrm{T}=(20 \pm 2){ }^{\circ} \mathrm{C}$. 


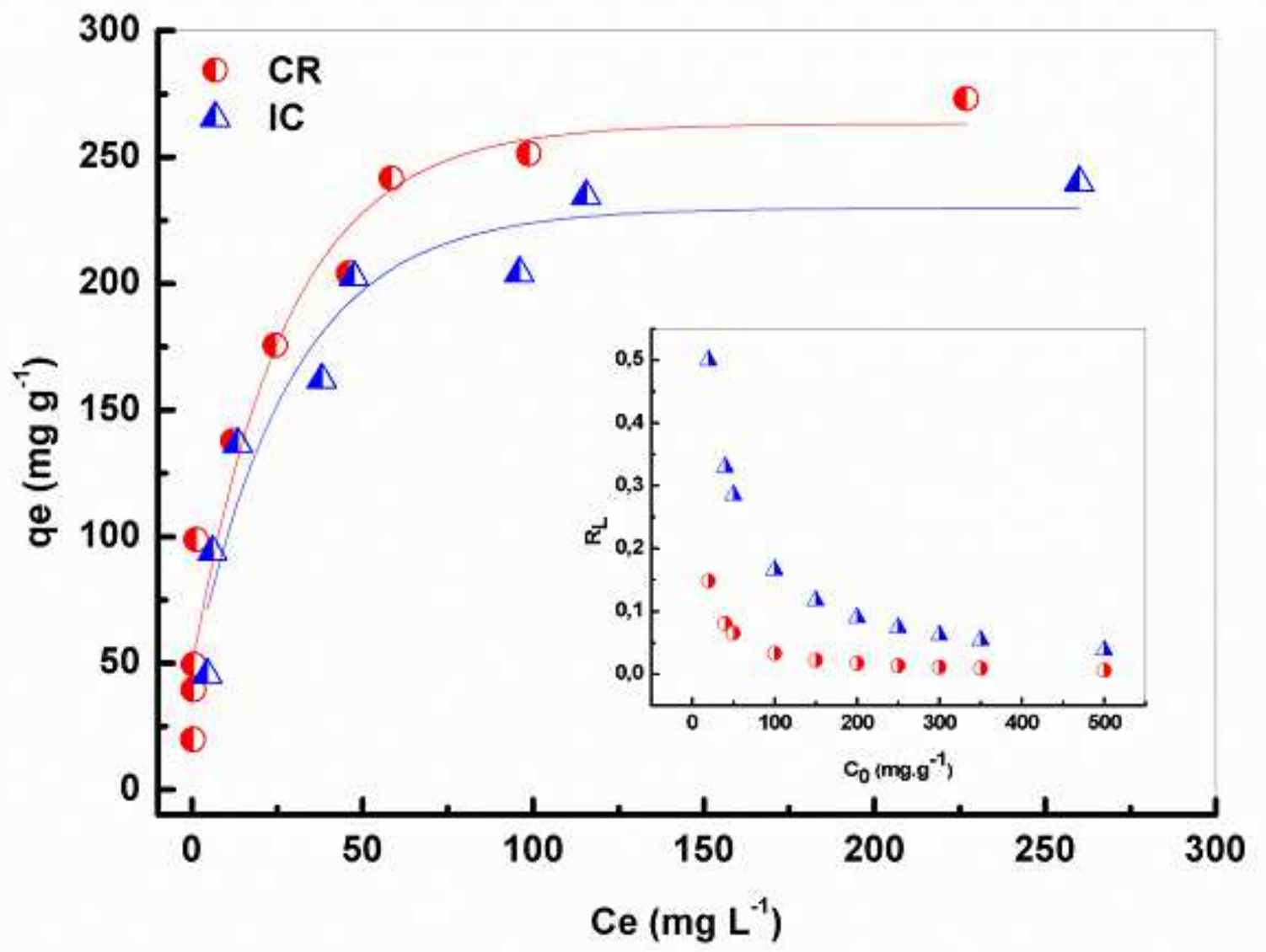

Figure 10

Equilibrium isotherms of $\mathrm{CR}$ and $\mathrm{IC}$ adsorption onto hybrid-Bentonite, with $\mathrm{pH}=6.6, \mathrm{~m} / \mathrm{v}=1 \mathrm{~g} \mathrm{~L}-1$, and $\mathrm{T}=$ $(20 \pm 2)^{\circ} \mathrm{C}$. 

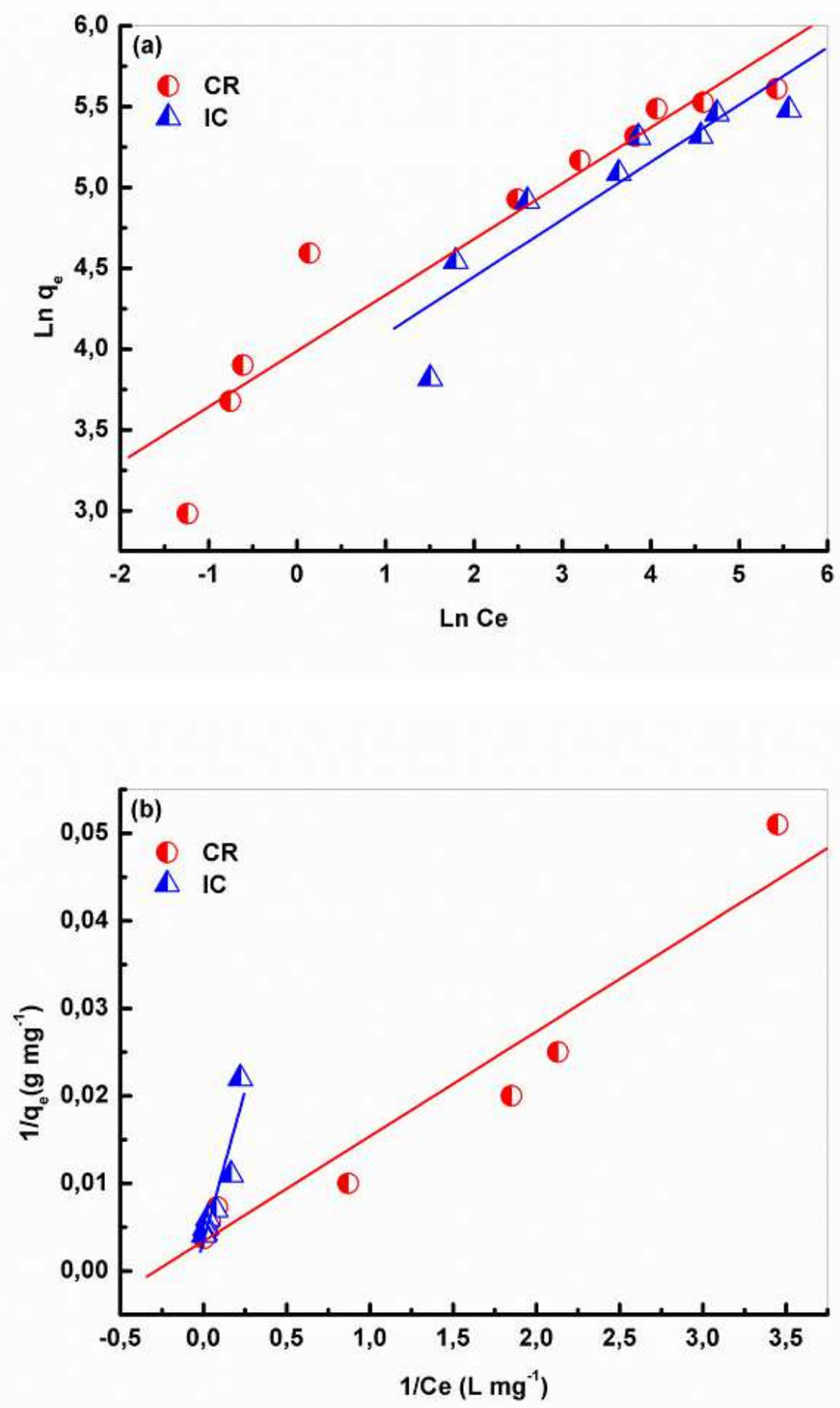

Figure 11

Adsorption isotherms of CR and IC on hybrid Bentonite fitted by Freundlich (a) and Langmuir (b) equations, with $\mathrm{pH}=6.6, \mathrm{~m} / \mathrm{v}=1 \mathrm{~g} \mathrm{~L}-1$, and $\mathrm{T}=(20 \pm 2){ }^{\circ} \mathrm{C}$. 